\title{
New pulmonary rehabilitation exercise for pulmonary fibrosis to improve the pulmonary function and quality of life of patients with idiopathic pulmonary fibrosis: a randomized control trial
}

\author{
Li Shen ${ }^{1,2 \#}$, Yuan Zhang ${ }^{2 \#}$, Yiliang Su ${ }^{2 \#}$, Dong Weng ${ }^{2 \#}$, Fen Zhang ${ }^{2}$, Qin $\mathrm{Wu}^{2}$, Tao Chen ${ }^{2}$, Qiuhong $\mathrm{Li}^{2}$, \\ Ying Zhou ${ }^{2}$, Yang $\mathrm{Hu}^{2}$, Xing Jiang ${ }^{2}$, Xiaofeng Jin ${ }^{2}$, Aihong Zhang ${ }^{3}$, Huiping $\mathrm{Li}^{2}$ \\ ${ }^{1}$ Medical College of Soochow University, Suzhou, China; ${ }^{2}$ Department of Respiratory Medicine, Shanghai Pulmonary Hospital, Tongji University, \\ School of Medicine, Shanghai, China; ${ }^{3}$ Department of Medical Statistics, Tongji University, School of Medicine, Shanghai, China \\ Contributions: (I) Conception and design: H Li, L Shen, Y Zhang, Y Su, D Weng; (II) Administrative support: H Li, A Zhang; (III) Provision of study \\ materials or patients: Y Zhang, Y Su, F Zhang, Q Li, Y Zhou, Y Hu; (IV) Collection and assembly of data: Q Wu, T Chen, X Jiang, X Jin, L Shen; (V) \\ Data analysis and interpretation: L Shen, A Zhang, D Weng, F Zhang; (VI) Manuscript writing: All authors; (VII) Final approval of manuscript: All \\ authors. \\ "These authors contributed equally to this work. \\ Correspondence to: Prof. Dr. Huiping Li, MD. Department of Respiratory Medicine, Shanghai Pulmonary Hospital, Tongji University, School of \\ Medicine, 507 Zheng Min Road, Shanghai 200433, China. Email: liw2013@126.com.
}

Background: The aim of our study is to investigate the impact of the simple breathing exercises (LHP's respiratory rehabilitation for pulmonary fibrosis, LHP's RRPF) on patients with idiopathic pulmonary fibrosis (IPF).

Methods: (I) The safety and effectiveness of LHP's RRPF were first verified in 20 healthy individuals. (II) A total of 101 patients with IPF administrated in Shanghai Pulmonary Hospital between January 2015 and May 2017 were screened, and 82 cases were randomly assigned to receive a 12-month LHP's RRPF program (exercise group) or usual medical care (control group). Lung function, chest X-ray, 6-minute walk distance (6MWD), quality of life (St. George's Respiratory Questionnaire, SGRQ), and EKG were measured at the $6^{\text {th }}$ and $12^{\text {th }}$ month during the trial.

Results: At the $6^{\text {th }}$ month visit, the exercise group showed improved SGRQ score and lung function parameters (FVC, FEV1, and DLCO). At the $12^{\text {th }}$ months visit, the exercise group had significantly improved SGRQ score, 6MWD, and lung function (FVC, FEV1, and DLCO) compared to the control group $(\mathrm{P}<0.05)$. No obvious adverse events occurred in the exercise group. The incidence of acute exacerbation and one-year mortality were $7.69 \%$ and $2.56 \%$, respectively in the exercise group, which were lower than those $(20.9 \%$ and $9.3 \%$, respectively) in the control group.

Conclusions: LHP's RRPF can delay the pulmonary function decline of patients with IPF and improve their quality of life. This breathing exercise may be an adjunct to pulmonary rehabilitation for IPF.

Keywords: LHP's respiratory rehabilitation for pulmonary fibrosis (LHP's RRPF); forced vital capacity; quality of life

Submitted Jan 11, 2021. Accepted for publication May 29, 2021.

doi: 10.21037/apm-21-71

View this article at: https://dx.doi.org/10.21037/apm-21-71 


\section{Introduction}

Idiopathic pulmonary fibrosis (IPF) is an interstitial lung disease with an unknown pathogenesis and chronic progression $(1,2)$. The end stage IPF presents damaged alveolar structure, pulmonary fibrosis with honeycomb, gradually reduced lung volume, and progressively declined lung function (3). IPF progression adversely affects the quality of life and survival of patients (4). The average survival of patients with confirmed IPF is only 2 to 5 years $(1,2,5)$. Except lung transplantation, effective therapies for IPF are still lacking $(1,2)$. Thus, effective preventive and therapeutic method that can successfully improve lung function and quality of life and extend survival remains an unmet need.

The International IPF Guidelines emphasize that lung rehabilitation is one of the key therapeutic approaches for IPF (6). However, current lung rehabilitation focuses on physical exercise of whole body (7-13) and the perform is very complex. We developed the breathing exercises named "LHP's Respiratory Rehabilitation for Pulmonary Fibrosis" (LHP's RRPF, Registration No. 2015-V-00432628) specific for patients with pulmonary fibrosis. LHP's RRPF designed based on the lung characteristics of patients with pulmonary fibrosis, such as reduced lung tissue elasticity, gradually decreased lung volume, and unable to tolerate intensive physical exercise because of hypoxia. In the current study, the safety and effectiveness of LHP's RRPF on improving lung ventilation was first verified in healthy people, and then a randomized control trial (http://www.chictr.org. cn/enindex.aspx, Trial No. ChiCTR-OOC-15005818, study protocol was in online https://cdn.amegroups.cn/ static/public/apm-21-71-1.pdf) to investigate the effect of LHP's RRPF on lung function and quality of life of IPF patients was performed. We present the following article in accordance with the CONSORT reporting checklist (available at https://dx.doi.org/10.21037/apm-21-71).

\section{Methods}

\section{The breathing exercise movements, safety, and effectiveness of LHP's RRPF}

Breathing Exercise of LHP's RRPF (Registration No.: 2015-V00432628) includes 3 consecutive sets of movements (Figure S1):

(I) Deep breath of the whole lung;

(II) Deep breath of unilateral lower lung;

(III) Deep breath of the upper lung.

Detailed methods are in Supplementary file 1 (Appendix 1).

\section{Lung ventilation efficiency test}

Briefly, Vibration Response Imaging (VRI) (VRIxp, DEEPBREEZE) can measure lung function during breathing at resting state. The principle of operation of VRI is displayed in Figure S2. Patients' maximal forced vital capacity (FVC) was used to estimate the lung volume of each lung section.

\section{Safety and effectiveness in healthy individuals}

Briefly, twenty healthy volunteers aged 40 to 50 (10 men and 10 women) completed the breathing exercises of LHP's RRPF. VRI was performed before and after the breathing exercises to determine the effectiveness on lung ventilation.

\section{Safety and effectiveness of LHP's RRPF in IPF patients}

\section{Patient inclusion and exclusion criteria}

Inclusion criteria: (I) patients were diagnosed with IPF (definite UIP) according to the 2013 and 2018 ATS/ERS/ JRS/ALAT guidelines $(14,15)$, and their condition was stable for at least one month; (II) 40 to 80 years of age, male or female; (III) were able to tolerate the breathing exercises; (IV) at stable state, arterial blood gas $\mathrm{PO}_{2}>60 \mathrm{mmHg}$ and $\mathrm{PCO}_{2}<50 \mathrm{mmHg}$; (V) 6MWD $\geq 100$ meters; (VI) had good compliance with the study protocol; (VII) were fully informed of study aims, methods, and potential adverse reactions, agreed to participate in the trial, and signed the informed consent form.

Exclusion criteria: (I) patients were unable to tolerate the breathing exercises; (II) had obvious pulmonary infection that required anti-infection treatment (patients had respiratory infection or systemic infection within 4 weeks of the enrollment); (III) had malignant tumors 5 years before the enrolment; (IV) participated in other clinical trials within 3 months of the enrolment; (V) had severe systemic diseases and organ dysfunction; (VI) were pregnant, nursing, planning for pregnancy, or unable to use effective contraceptive; (VII) had medical conditions that were considered unsuitable for the trial by the investigators.

The screening and single-blind randomization were completed at the Department of Respiratory Medicine, Shanghai Pulmonary Hospital, Tongji University. The trial was conducted in accordance with the Declaration of Helsinki (as revised in 2013). The study has been approved by the Institutional Review Board of Shanghai Pulmonary Hospital (approval No. K14-156). All patients enrolled in the study signed informed consent. Patients' baseline data were collected and are presented in Table 1 . 
Table 1 Patient baseline data at the enrollment (mean \pm standard deviation)

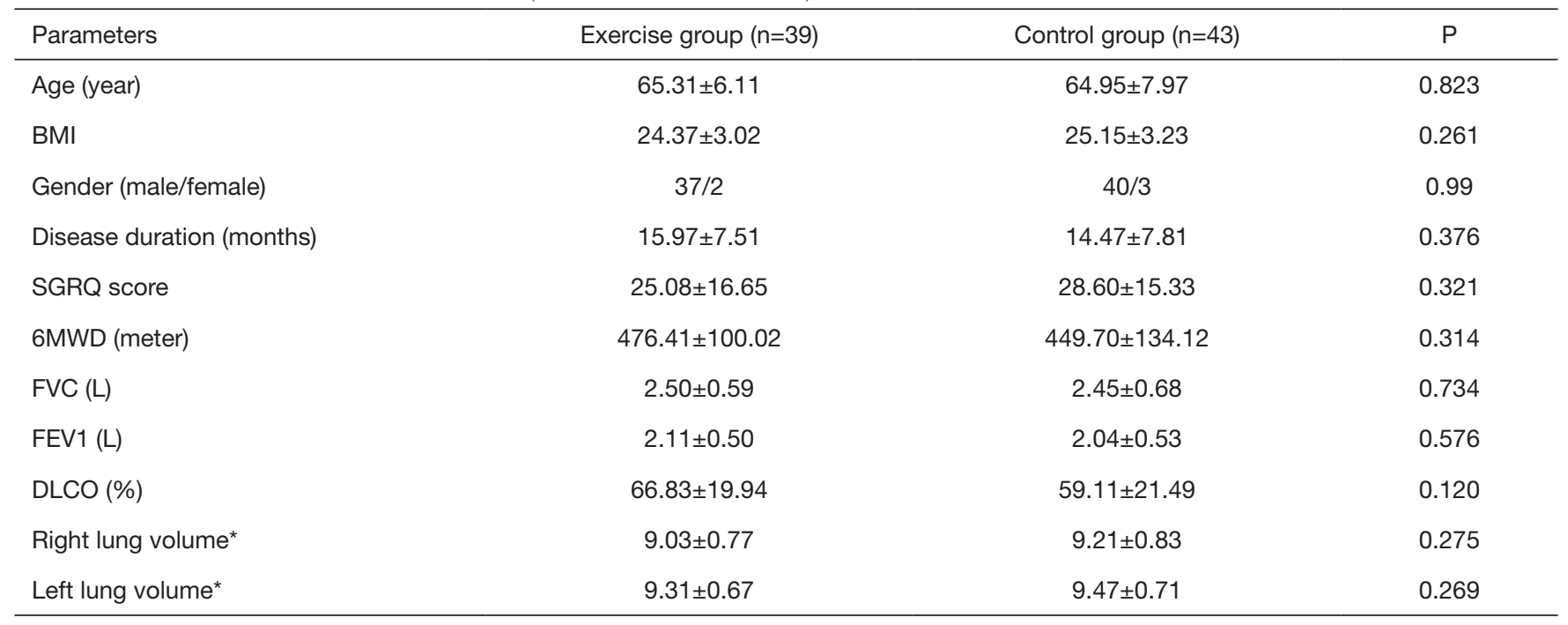

*, lung volume measurement based on chest X-ray: at the end of deep inhalation, unilateral septal position relative to the position of the posterior rib position. BMI, body mass index; SGRQ, St. George's Respiratory Questionnaire; 6MWD, six-minute walk distance; FVC, forced vital capacity; FEV1, forced expiratory volume in one second; DLCO, diffusing capacity of the lungs for carbon monoxide.

\section{Study design and randomization}

The sample size was calculated based on an estimated $5 \%$ improvement in FVC in lung function, and the estimated number of IPF cases was at least 44 for total, excluding the loss of follow-up rate of $10 \%$ patients. The study schedule is briefly displayed in Figure S3. Patients were randomly assigned to the LHP's RRPF exercise (exercise group) or control group using sealed envelopes with randomized results by SAS analysis software (16), which were prepared and shuffled before the start of the study by an independent person unrelated to the study protocol. The envelope was opened by the allocator sequentially, only after the participant's name was written on it. Both groups of the patients were scheduled to have clinic visits at the $6^{\text {th }}$ and/or $12^{\text {th }}$ month.

The patients assigned to the exercise group were trained to do the LHP's RRPF exercise [Supplementary file 1 (Appendix 1) and Figure S1] and confirmed by investigator, then they attend a 12 -month rehabilitation program. They repeated the exercise 3 times daily (4 to 6 minutes each time) and rested for 1 minute after each time. Patients continued their existing therapies during the trial at least for 1 year. The patients assigned to the control group were treated with their existing therapies, with basic medical care and an identical medical follow-up, similarly to those in exercise group. If patients developed acute exacerbation during the trial, the patients were withdrawn from the trial and treated immediately.

\section{Effectiveness and safety assessment}

\section{Primary endpoints}

Briefly, the study primary endpoints were changes in FVC and lung volume. Lung function was determined according to the 2005 ATS/ERS Guidelines (17). Changes in FVC after the breathing exercises were used to estimate the effectiveness of LHP's RRPF. Chest X-ray was performed at the beginning and end of the trial. Lung volume was determined by the position of the left and right transverses relative to the position of the posterior rib on the $\mathrm{X}$-ray image. Changes in lung volume after the breathing exercises were measured.

\section{Secondary endpoints}

Briefly, the study secondary endpoints included 6MWD (18), quality of life score (St. George's Respiratory Questionnaire, SGRQ score) (19), forced expiratory volume in one second (FEV1) (17), and diffusing capacity of the lungs for carbon monoxide (DLCO).

\section{Safety measurement}

Electrocardiogram (EKG) was performed to assess the effect of the breathing exercise on cardiac function. Patients underwent EKG at the beginning of the trial and the $6^{\text {th }}$ and 
$12^{\text {th }}$ month clinic visits.

\section{Statistical analysis}

Paired $t$-test was used to compare the heart rate and blood oxygen saturation of healthy volunteers before the breathing exercise, right after the exercise, and one minute after the end of the exercise.

Independent sample $t$-test was used to analyze the baseline data of enrolled patients, including age, BMI, gender, disease duration, SGRQ score, 6MWD, FVC, FEV1, DLCO, and lung volume.

Unstructured covariance matrix was used in the linear mixed effect model (likelihood-ratio is the minimal), $\mathrm{P}<0.05$ was considered significantly different. The statistical analysis software IBMSPSS24 was used.

\section{Results}

\section{Effectiveness and safety of LHP's RRPF in bealthy volunteers}

A total of 20 healthy volunteers participated in the breathing exercise. The lung volume of the healthy volunteers was monitored by VRI (QLD, MEF, EVP, Figure S4) during the exercise.

In addition, compared with the heart rate at resting state, the heart rate of every healthy volunteer was significantly increased immediately after completion of one- time breathing exercise, and the heart rate restored to the level at the resting state after the subject rested for one minute. Pulse oxygen saturation was not changed significantly by the exercise (Table S1).

In summary, those data support that LHP's RRPF appears to be safe for healthy people and the three sets of movements of the breathing exercise can effectively expand the volume of different parts of the lung. These results indicate that the exercises might be suitable for IPF patients.

\section{Effectiveness and safety of LHP's RRPF in IPF patients}

A total of 101 patients with IPF treated at the Department of Respiratory Medicine of Shanghai Pulmonary Hospital between January 2015 and May 2017 were screened. Of the 101 inpatients, 19 patients were excluded (2 patients can't follow up, 8 patients' $6 \mathrm{MWT}$ were $<100 \mathrm{~m}, 9$ patients' arterial blood gas $\mathrm{PO}_{2}$ were $<60 \mathrm{mmHg}$ ), 82 met the inclusion criteria and participated in the trial and were randomized to the breathing exercise group (39 cases) and non-exercise control group (43 cases). In the exercise group, 3 withdrew because of IPF exacerbation (one died), 28 finished the 6-month program and had $6^{\text {th }}$ months clinic visit data, then 22 of 28 continually finished 12 months program and had the 12 -month clinic visit data, 8 cases finished 12 months program but only had the 12-month clinic visit data. In the control group, 7 withdrew because of IPF exacerbation (three died); 1 withdrew because of death from lumbar fracture repair surgery; 1 withdrew because of lung cancer; 22 had the 6-month clinic visit data (17 of them had the 12-month clinic visit data); 12 only had the 12-month clinic visit data (Figure 1).

The two group patients showed similar baseline data (Table 1).

\section{Results from the $6 \mathrm{t}^{\mathrm{h}}$ month clinic visit}

A total of 50 patients had the $6^{\text {th }}$ month clinic visit data, including 28 patients in the exercise group and 22 patients in the control group. The average compliance rate of exercise group is $93.60 \%$. The data are presented in Table 2. Although FVC at the $6^{\text {th }}$ month of the trial reduced compared with the baseline values in both groups, the exercise group showed significantly less reduction in FVC than the control group $(\mathrm{P}=0.022$, Figure S5A). SGRQ score has no difference between two groups. SGRQ score was reduced in the majority of patients in the exercise group (Figure S5B). The average changes in the SGRQ score ( $\triangle$ SGRQ) was negative in the exercise group and positive in the control group, the absolute $\triangle \mathrm{SGRQ}$ was significantly bigger in the exercise group $(\mathrm{P}=0.016)$. The $6 \mathrm{MWD}$ at the $6^{\text {th }}$ month of the exercise group was similar to that at baseline, whereas the $6 \mathrm{MWD}$ of the control group was reduced (Figure S5C). The average $\triangle 6 \mathrm{MWD}$ of the control group was a significant reduction from the baseline. The reduction in FEV1 at the $6^{\text {th }}$ month of the exercise group was significantly less than that of the control group $(\mathrm{P}=0.017$, Figure S5D). The average change in DLCO $(\triangle \mathrm{DLCO})$ was an increase in the exercise group, but was a reduction in the control group, and the absolute $\triangle \mathrm{DLCO}$ was significantly greater in the control group than in the exercise group $(\mathrm{P}<0.001$, Figure S5E). Thus, FVC, SGRQ, FEV1, and DLCO were significantly improved in the exercise group compared with the control group. The exercise group also showed improvement in $6 \mathrm{MWD}$ although with no statistical significance. 


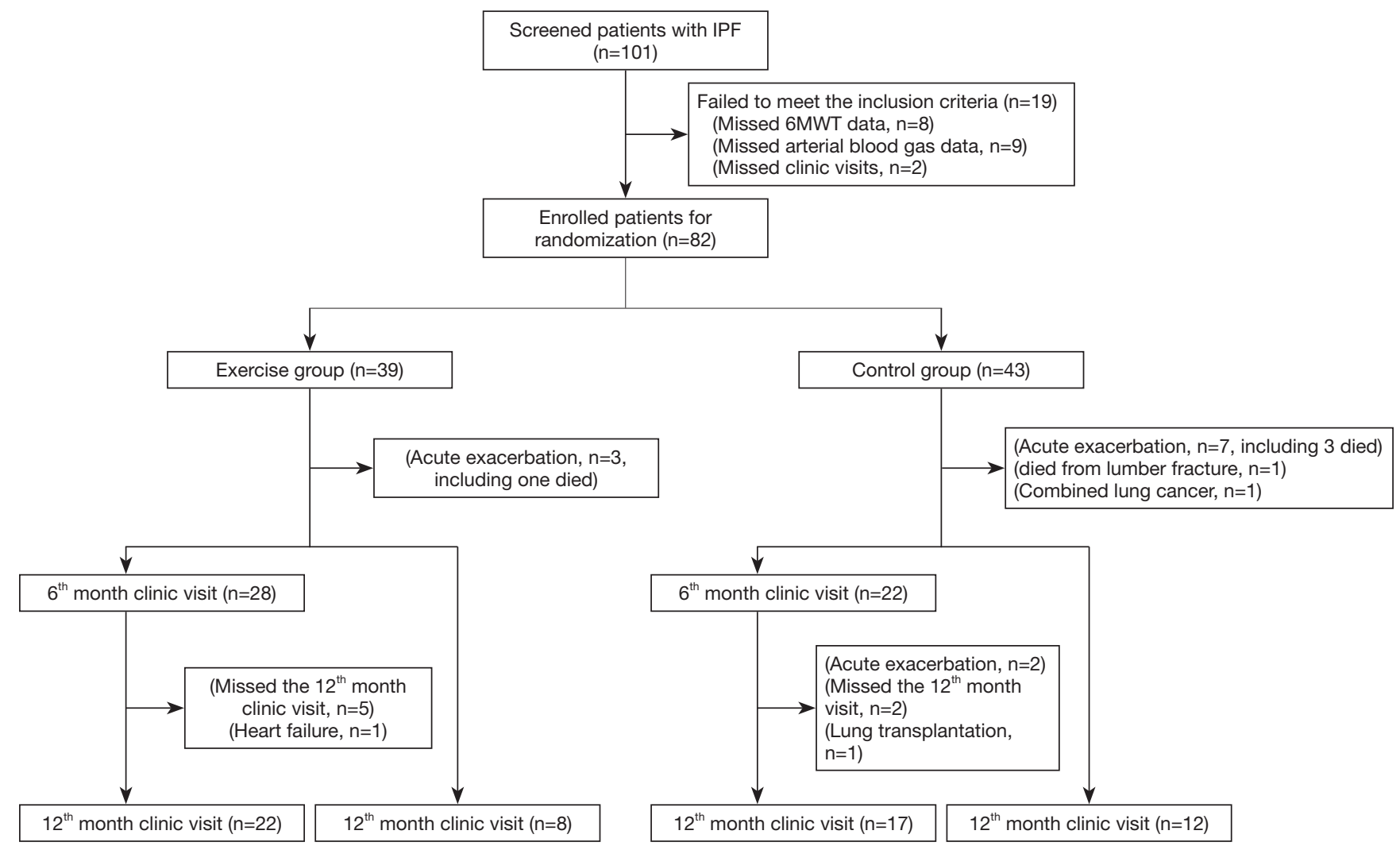

Figure 1 Patient flow chart. IPF, idiopathic pulmonary fibrosis.

Table 2 Comparison of values at the $6^{\text {th }}$ month visit versus the baseline values $(\mathrm{n}=50)$

\begin{tabular}{lccc}
\hline Parameters & Exercise group $(\mathrm{n}=28)$ & Control group $(\mathrm{n}=22)$ & $\mathrm{P}$ \\
\hline$\triangle$ SGRQ score & $-5.86 \pm 10.39$ & $1.90 \pm 10.32$ & 0.016 \\
$\triangle 6$ MWD (meter) & $-23.93 \pm 91.98$ & $-57.30 \pm 92.43$ & 0.266 \\
$\triangle$ FVC (L) & $-0.007 \pm 0.220$ & $-0.155 \pm 0.221$ & 0.022 \\
$\triangle$ FEV1 (L) & $-0.008 \pm 0.170$ & $-0.128 \pm 0.170$ & 0.017 \\
$\triangle$ DLCO (\%) & $4.89 \pm 10.30$ & $-11.422 \pm 10.38$ & $<0.001$ \\
\hline
\end{tabular}

$\Delta$ : values at the $6^{\text {th }}$ month visit - baseline values. For the analysis of FVC, FEV1, and DLCO, 26 patients from the exercise group and 20 patients from the control group were included. Two patients from each group did not have lung function parameters. SGRQ, St. George's Respiratory Questionnaire; 6MWD, six-minute walk distance; FVC, forced vital capacity; FEV1, forced expiratory volume in one second; DLCO, diffusing capacity of the lungs for carbon monoxide.

\section{Results from the $12^{\text {th }}$ month clinic visit}

A total of 59 patients returned to the $12^{\text {th }}$ month clinic visit (Table 3). The average compliance rate of exercise group is $94.71 \%$. At the $12^{\text {th }}$ month of the trial, Ten patients from the exercise group showed increased lung volume on chest X-ray (0.5-1, intercostal, Figure S6A). None of the patients in the exercise group had reduced lung volume at the $12^{\text {th }}$ month of the trial. In contrast, 6 patients from the control group showed reduced lung volume (0.5-1 intercostal, Figure S6B). The exercise group showed significantly less reduction in FVC than the control group $(\mathrm{P}=0.001$, Figure $\mathrm{S} 7 \mathrm{~A}, \mathrm{~B})$. The average $\triangle \mathrm{SGRQ}$ at the $12^{\text {th }}$ month was negative in the exercise group and positive in the control group, and the absolute $\triangle \mathrm{SGRQ}$ was significantly different 
Table 3 Comparison of values at the $12^{\text {th }}$ month visit versus the baseline values $(\mathrm{n}=59)$

\begin{tabular}{lccc}
\hline Parameters & Exercise group $(\mathrm{n}=30)$ & Control group $(\mathrm{n}=29)$ & $\mathrm{P}$ \\
\hline$\triangle$ SGRQ score & $-3.723 \pm 10.35$ & $4.806 \pm 10.359$ & 0.003 \\
$\triangle 6 \mathrm{MWD}$ (meter) & $-27.272 \pm 91.668$ & $-82.297 \pm 91.753$ & 0.041 \\
$\Delta$ FVC (L) & $-0.003 \pm 0.221$ & $-0.249 \pm 0.222$ & 0.001 \\
$\triangle$ FEV1 (L) & $-0.005 \pm 0.171$ & $-0.200 \pm 0.171$ & 0.001 \\
$\triangle$ DLCO (\%) & $-1.338 \pm 10.274$ & $-10.912 \pm 10.318$ & 0.003 \\
\hline
\end{tabular}

$\Delta$ : values at the $12^{\text {th }}$ month visit - baseline values. For the analysis of FVC and FEV1, 27 patients from the control group were included. For the analysis of DLCO, 28 patients from the exercise group and 23 patients from the control group were included; 2 patients from the exercise group and 5 from the control group did not have DLCO data. SGRQ, St. George's Respiratory Questionnaire; 6MWD, six-minute walk distance; FVC, forced vital capacity; FEV1, forced expiratory volume in one second; DLCO, diffusing capacity of the lungs for carbon monoxide.

in the two groups $(\mathrm{P}=0.003$, Figure $\mathrm{S} 7 \mathrm{C}, \mathrm{D})$. The average $\triangle 6 \mathrm{MWD}$ was negative in both groups, and the reduction in $6 \mathrm{MWD}$ was significantly less in the exercise group than in the control group $(\mathrm{P}=0.041$, Figure $\mathrm{S} 7 \mathrm{E}, \mathrm{F})$. The average reduction in FEV1 was significantly less in the exercise group than in the control group $(\mathrm{P}=0.001$, Figure $\mathrm{S} 7 \mathrm{G}, \mathrm{H})$. The average reduction in DLCO was significantly less in the exercise group than in the control group $(\mathrm{P}=0.003$, Figure S7I,J).

No new arrhythmias or other adverse events related to the LHP's RRPF exercise were reported from the patient's diary and follow-up electrocardiogram results. Of the 82 enrolled IPF patients, 3 from the exercise group and 9 from the control group developed acute exacerbation during the trial, but the difference was not significantly different (Table S2). The one-year mortality of the exercise group was lower than that of the control group although the difference was not statistically significant (Figure S8 and Table S3).

\section{Discussion}

The current IPF Diagnosis and Treatment Guidelines $(2,6,16)$ state that no drugs can reverse the initiation and progression of fibrosis. The anti-fibrotic drugs that are currently commonly used in clinical practice, such as pirfenidone, nintedanib, and acetylcysteine. However, the effects of these drugs are not satisfactory (20-22). A previous study proved that lung rehabilitation was the most effective for patients with ILD, particularly for IPF (23). Lung rehabilitation for patients with IPF includes lung rehabilitation exercise (24), symptom management (25), lung rehabilitation education, and daily care (26). Lung rehabilitation exercises can improve cardiovascular function, effectively reduce IPF-associated cardiovascular morbidity and mortality (27), improve the physical activity and quality of life of patients with late stage IPF $(28,29)$, significantly improve the scores of SGRQ-1 and International Physical Activity Questionnaire in 24 patients with $\operatorname{IPF}(30,31)$, and extend the duration of constant-load exercise in patients with moderate to severe IPF (32). Patients need to adhere to the exercise for a long time. When the exercises stop, patients' exercise capacity reverses to the baseline level (33). Thus, it is necessary to develop breathing exercises that are safe, effective, easy to learn, cost effective, and suitable for patients with pulmonary fibrosis.

LHP's RRPF was a set of breathing exercises and designed according to the characteristics of patients with lung fibrosis, such as reduced lung tissue elasticity, limited lung expansion, decreased lung volume, and substantially reduced vital capacity. Slowly repeating three of simple movements combined with deep breathing can practice the respiratory muscles time and again, maintain lung elasticity, slowdown lung volume reduction, delay lung function decline, reduce breathing difficulties, improve exercise endurance and quality of life.

In this trial, we first validated the safety and effectiveness of the breathing exercises on healthy volunteers by using VRI system to monitor the lung. Then we investigated the safety and effectiveness of LHP's RRPF on patients with IPF. The control group was given medication and normal life, and was given regular guidance on disease rehabilitation (notes for disease attention, etc.). In view of the limitations of Chinese respiratory rehabilitation therapists, no patients received regular physical exercise or other rehabilitation exercises. In addition to the prescribed 
breathing exercises, the exercise group did not receive other breathing rehabilitation exercises. We found that at the $6^{\text {th }}$ month of the trial, FVC reduction in the exercise group were significantly less than those in the control group, and SGRQ, FEV1, and DLCO improved significantly in the exercise group. The duration of the breathing exercise of our study is longer than that in the previous studies (10-13). At the $12^{\text {th }}$ month of the trial, the reductions in FVC, FEV1, DLCO in the exercise group was significantly less than those in the control group, and these results are consistent with those from Swigris et al. (12). The breathing exercises can slow down the decline of lung functional and physical performance (6MWT) in IPF patients and improve the quality of life (SGRQ). After $12^{\text {th }}$ month of breathing exercise, there was no breathing exercise-associated adverse event including EKG result indicating that breathing exercises is safe for IPF patients.

Our study has shown several advantages of LHP's RRPF. (I) The design is scientific for pulmonary fibrosis patients, it is simple, and effective. Patients can easily learn the 3 sets of simple limb movements combined with deep breathing after being properly trained. During the exercises, the slow, gentle, and continuous movements can help patients to maintain lung elasticity, delay lung function decline, and improve quality of life. (II) The exercise is safe and has few side effects. IPF patients usually have limited physical activity capacity and some of them with hypoxemia, hence they may not be fit for excessive whole-body activity (7). LHP's RRPF focus on exercising the respiratory muscles and minimally involve other muscles of whole body. Thus, the exercises did not cause excessive oxygen consumption. Duration of the exercises only need 4-6 minutes and can be tolerated well. Patients with hypoxia can perform the breathing exercise safely when they have oxygen inhalation. If patients have a cough, they can perform the exercises with antitussive drugs. (III) The exercises do not need any cost, because these breathing exercises do not require any specialized rehabilitation center and equipment. In addition, the quality control of patients in the process of exercise is the key to respiratory exercise, which needs to remind patients in the future clinical application, and strengthen the guidance and supervision of exercise in order to achieve better results.

Obviously, there was a certain rate of loss of follow-up in this study, and we also found that the consistency and standardization of breathing exercises were the difficulties in this study. In the process of follow-up, the changes of diseases and the difficulty of follow-up make us lose some patient data. In the exercise guidance of respiratory exercises, researchers are often required to supervise and guide patients' exercise, so that patients can achieve the best exercise effect. In addition, for patients with moderate to severe IPF, especially those who cannot be separated from oxygen inhalation support, it is difficult for them to carry out breathing exercise. Therefore, this breathing exercise can only be carried out in patients with mild to moderate IPF.

\section{Conclusions}

In summary, LHP's RRPF is safe, effective, easy to perform, no cost, and suitable for patients with IPF. The LHP's RRPF may be an adjunct to pulmonary rehabilitation for IPF.

\section{Acknowledgments}

Funding: This study was funded by grants from the National Science Foundation of China (Grant No. 81730002, 81670055, 81670056, 91442103, 81500052, and 81570057), Ministry of Science and Technology of the People's Republic of China (2016YFC1100200 and 2016YFC1100204), Shanghai Family Planning Commission Health Industry Clinical Research Project (20184Y0084), and Shanghai Hospital Development Center (16CR3054A).

\section{Footnote}

Reporting Checklist: The authors have completed the CONSORT reporting checklist. Available at http://dx.doi. org/10.21037/apm-21-71

Data Sharing Statement: Available at http://dx.doi. org/10.21037/apm-21-71

Conflicts of Interest: All authors have completed the ICMJE uniform disclosure form (available at http://dx.doi. org/10.21037/apm-21-71). The authors have no conflicts of interest to declare.

Ethical Statement: The authors are accountable for all aspects of the work in ensuring that questions related to the accuracy or integrity of any part of the work are appropriately investigated and resolved. The trial was conducted in accordance with the Declaration of Helsinki (as revised in 2013). The study was approved by the 
Institutional Ethics Committee of Shanghai Pulmonary Hospital (No. K14-156). All patients enrolled in the study signed informed consent.

Open Access Statement: This is an Open Access article distributed in accordance with the Creative Commons Attribution-NonCommercial-NoDerivs 4.0 International License (CC BY-NC-ND 4.0), which permits the noncommercial replication and distribution of the article with the strict proviso that no changes or edits are made and the original work is properly cited (including links to both the formal publication through the relevant DOI and the license). See: https://creativecommons.org/licenses/by-nc-nd/4.0/.

\section{References}

1. Frankel SK, Schwarz MI. Update in idiopathic pulmonary fibrosis. Curr Opin Pulm Med 2009;15:463-9.

2. Raghu G, Collard HR, Egan JJ, et al. ATS/ERS/JRS/ ALAT Committee on Idiopathic Pulmonary Fibrosis: An official ATS/ERS/JRS/ALAT statement: idiopathic pulmonary fibrosis: evidence-based guidelines for diagnosis and management. Am J Respir Crit Care Med 2011;183:788-824.

3. American Thoracic Society. Idiopathic pulmonary fibrosis: diagnosis and treatment. International consensus statement. American Thoracic Society (ATS), and the European Respiratory Society (ERS). Am J Respir Crit Care Med 2000;161:646-64.

4. Schmidt SL, Tayob N, Han MK, et al. Predicting Pulmonary Fibrosis Disease Course From Past Trends in Pulmonary Function. Chest 2014;145:579-85.

5. Meltzer EB, Noble PW. Idiopathic pulmonary fibrosis. Orphanet J Rare Dis 2008;3:8.

6. Raghu G, Rochwerg B, Zhang Y, et al. American Thoracic Society;European Respiratory society;Japanese Respiratory Society;Latin American Thoracic Association. An Official ATS/ERS/JRS/ALAT Clinical Practice Guideline: Treatment of Idiopathic Pulmonary Fibrosis. An Update of the 2011 Clinical Practice Guideline. Am J Respir Crit Care 2015;192:e3-19.

7. Spruit MA, Singh SJ, Garvey C, et al. An Official American Thoracic Society/European Respiratory Society Statement: Key Concepts and Advances in Pulmonary Rehabilitation. Am J Respir Crit Care Med 2013;188:e13-64.

8. Nishiyama O, Kondoh Y, Kimura T, et al. Effects of pulmonary rehabilitation in patients with idiopathic pulmonary fibrosis. Respirology 2008;13:394-9.

9. Bajwah S, Ross JR, Peacock JL, et al. Interventions to improve symptoms and quality of life of patients with fibrotic intersitial lung disease: a systematic review of the literature. Thorax 2013;68:867-79.

10. Vainshelboim B, Oliveira J, Yehoshua L, et al. Exercise training-based pulmonary rehabilitation program is clinically beneficial for idiopathic pulmonary fibrosis. Respiration 2014;88:378-88.

11. Vainshelboim B, Oliveira J, Fox BD, et al. Longterm effects of a 12 -week exercise training program on clinical outcomes in idiopathic pulmonary fibrosis. Lung 2015;193:345-54.

12. Swigris JJ, Fairclough DL, Morrison M, et al. Benefits of Pulmonary Rehabilitation in Idiopathic Pulmonary Fibrosis. Respir Care 2011;56:783-9.

13. Rifaat N, Anwar E, Ali YM, et al. Value of pulmonary rehabilitation in with idiopathic pulmonary fibrosis. Egyptian Journal of Chest Diseases and Tuberculosis 2014;63:1013-7.

14. Travis WD, Costabel U, Hansell DM, et al. ATS/ERS Committee on Idiopathic Interstitial Pneumonias. An official American Thoracic Society/European Respiratory Society statement: Update of the international multidisciplinary classification of the idiopathic interstitial pneumonias. Am J Respir Crit Care Med 2013;188:733-48.

15. Raghu G, Remy-Jardin M, Myers JL, et al. American Thoracic Society, European Respiratory Society, Japanese Respiratory Society, and Latin American Thoracic Society. Diagnosis of Idiopathic Pulmonary Fibrosis An Official ATS/ERS/JRS/ALAT Clinical Practice Guideline. Am J Respir Crit Care Med 2018;198:e44-e68.

16. Doig GS, Simpson F. Randomization and allocation concealment: a practical guide for researchers. J Crit Care 2005;20:187-91; discussion 191-3.

17. Miller A, Enright PL. PFT Interpretive Strategies: American Thoracic Society/European Respiratory Society 2005 Guideline Gaps. Respir Care 2012;57:127-33; discussion 133-5.

18. ATS Committee on Proficiency Standards for Clinical Pulmonary Function Laboratories. ATS statement: guidelines for the six-minute walk test. Am J Respir Crit Care Med 2002;166:111-7. Erratum in: Am J Respir Crit Care Med 2016;193:1185.

19. Barr JT, Schumacher GE, Freeman S, et al. American Translation, Modification, and Validation of the St. George's Respiratory Questionnaire. Clin Ther 
2000;22:1121-45.

20. Idiopathic Pulmonary Fibrosis Clinical Research Network, Martinez FJ, de Andrade JA, et al. Randomized trial of acetylcysteine in idiopathic pulmonary fibrosis. N Engl J Med 2014;370:2093-101.

21. Noble PW, Albera C, Bradford WZ, et al. CAPACITY Study Group.. Pirfenidone in patients with idiopathic pulmonary fibrosis (CAPACITY): two randomised trials. Lancet 2011;377:1760-9.

22. Richeldi L, du Bois RM, Raghu G, et al. Efficacy and safety of nintedanib in idiopathic pulmonary fibrosis. $\mathrm{N}$ Engl J Med 2014;370:2071-82.

23. Nakazawa A, Cox NS, Holland AE. Current best practice in rehabilitation in interstitial lung disease. Ther Adv Respir Dis 2017;11:115-28.

24. Benton MJ, Graham HL. Maintaining quality of life in IPF patients: What role should pulmonary rehabilitation play? Respirology 2017;22:841-2.

25. Garibaldi BT, Danoff SK. Symptom-based management of the idiopathic interstitial pneumonia. Respirology 2016;21:1357-65.

26. Igai Y. End-of-life trajectory of coping and self-care of patients with idiopathic pulmonary fibrosis: a metasynthesis using meta-ethnography. Jpn J Nurs Sci 2019;16:47-61.

27. Vainshelboim B, Kramer MR, Fox BD, et al. Supervised exercise training improves exercise cardiovascular function in idiopathic pulmonary fibrosis. Eur J Phys Rehabil Med 2017;53:209-18.

28. da Fontoura FF, Berton DC, Watte G, et al. Pulmonary rehabilitation in patients with advanced idiopathic pulmonary fibrosis referred for lung transplantation. J Cardiopulm Rehabil Prev 2018;38:131-4.

29. Perez-Bogerd S, Wuyts W, Barbier V, et al. Short and long-term effects of pulmonary rehabilitation in interstitial lung diseases: a randomised controlled trial. Respir Res 2018;19:182.

30. Arizono S, Taniguchi H, Sakamoto K, et al. Endurance time is the most responsive exercise measurement in idiopathic pulmonary fibrosis. Respir Care 2014;59:1108-15.

31. Gaunaurd IA, Gómez-Marín OW, Ramos CF, et al. Physical activity and quality of life improvements of patients with idiopathic pulmonary fibrosis completing a pulmonary rehabilitation program. Respir Care 2014;59:1872-9.

32. Jackson RM, Gómez-Marín OW, Ramos CF, et al. Exercise limitation in ipf patients: a randomized trial of pulmonary rehabilitation. Lung 2014;192:367-76.

33. Vainshelboim B, Fox BD, Kramer MR, et al. Short-term improvement in physical activity and body composition after supervised exercise training program in idiopathic pulmonary fibrosis. Arch Phys Med Rehabil 2016;97:788-97.
Cite this article as: Shen L, Zhang Y, Su Y, Weng D, Zhang F, Wu Q, Chen T, Li Q, Zhou Y, Hu Y, Jiang X, Jin X, Zhang A, Li H. New pulmonary rehabilitation exercise for pulmonary fibrosis to improve the pulmonary function and quality of life of patients with idiopathic pulmonary fibrosis: a randomized control trial. Ann Palliat Med 2021;10(7):7289-7297. doi: 10.21037/ apm-21-71 


\section{Supplementary File 1}

\section{Supplementary Detailed Methods}

1. The Breathing Exercise Movements, Safety, and Effectiveness of LHP's RRPF

1.1 Breathing Exercise Movements of LHP's RRPF (Registration No.: 2015-V-00432628)

LHP's RRPF includes the following 3 consecutive sets of movements (Figure S1):

(1). Deep breath of the whole lung.

Patients stood upright, separated the two feet at the shoulder width, and placed both arms on the outer thighs. Then, patients raised both arms outward slowly and inhaled deeply till both hands closed over the top of the head. Subsequently, patients lowered both arms slowly and exhaled deeply till both arms returned to their original position. Patients repeated these movements 4 to 6 times within one minute (Figure S1A).

(2). Deep breath of unilateral lower lung.

Patients stood upright, separated the two feet at the shoulder width, and placed both arms on the outer thighs. Then, patients raised the right arm outward slowly, bended the torso leftward to approximately $30-60^{\circ}$ angle, and inhaled deeply. Subsequently, patients exhaled deeply and lowered the right arm to its original position. Patients repeated the movements using the left arm. These movements were repeated 4 to 6 times within one minute (Figure S1B).

(3). Deep breath of the upper lung.

Patients stood upright, separated the two feet at the shoulder width, and placed both arms on the outer thighs. Then, patients crossed the two hands at the back of the neck, bended the head and neck forward, and exhaled deeply. Subsequently, patients kept the two hands crossed at the back of the neck, moved both arms backward, raised the head and neck slowly, and inhaled deeply. These movements were repeated 4 to 6 times within one minute (Figure S1C).

During the breathing exercises, patients should make sure that the movements are done properly, but they should avoid overdoing the exercises. The exercises should be done step by step but not cause fatigue or exhaustion. If patients experience over- ventilation during the breathing exercises, then oxygen inhalation should be allowed. If cough increases during the breathing exercises, antitussive drugs should be administered.

\subsection{Lung Ventilation Efficiency Test}

Vibration Response Imaging (VRI) (VRIxp, DEEPBREEZE) can measure lung function during breathing at resting state. Compared with conventional methods, VRI has substantial advantages. VRI can monitor the dynamic changes in lung volume and identify lesions directly, rapidly, and accurately. It can also discover abnormal breathing sounds in the lung with a high sensitivity and clearly illustrate the changes in lung volume in different regions (maximum energy frame, MEF). VRI has no impact on patient's condition. Thus, it is a safe and reliable method to evaluate the effectiveness of breathing exercises. The principle of operation of VRI is displayed in Figure S2. The lung volume and MEF during the breathing exercises were compared with those at resting state. VRI system divides the bilateral lung into upper, middle, and lower sections, calculates the percentage of each section, and configures the percentage quantitative lung data (QLD) map. Patients' maximal forced vital capacity (FVC) was used by the VRI system to estimate the lung volume of each lung section.

\subsection{Safety and Effectiveness of LHP's RRPF in Healthy Individuals}

Twenty healthy volunteers aged 40 to 50 years (10 men and 10 women) completed the breathing exercises of LHP's RRPF. VRI was performed before and after the breathing exercises to determine the effectiveness of LHP's RRPF on lung ventilation. The subject rested for one minute before and after each set of movement. Blood oxygen saturation and electrocardiogram were measured 3 times to determine the safety of LHP's RRPF.

\section{Safety and Effectiveness of LHP's RRPF in Patients with IPF}

2.1 Patient Inclusion and Exclusion Criteria

Inclusion criteria: 1) patients were diagnosed with IPF (definite UIP) according to the 2013 and 2018 ATS/ERS/ JRS/ALAT guidelines $[14,15]$, and their IPF condition was stable for at least one month; 2) 40 to 80 years of age, male or female; 3 ) were able to tolerate the breathing exercises; 4) at stable state, arterial blood gas $\mathrm{PO}_{2}>60 \mathrm{mmHg}$ and $\mathrm{PCO}_{2}<50 \mathrm{mmHg}$; 5) $6 \mathrm{MWD} \geq 100$ meters; 6) had good compliance with the study protocol; 7) were fully informed of study aims, methods, and potential adverse reactions, 
agreed to participate in the trial, and signed the informed consent form.

Exclusion criteria: 1) patients were unable to tolerate the breathing exercises; 2 ) had obvious lung infection that required anti-infection treatment (patients had respiratory infection or systemic infection within 4 weeks of the enrollment); 3) had malignant tumors 5 years before the enrolment; 4) participated in other clinical trials within 3 months of the enrolment; 5) had severe systemic diseases and organ dysfunction; 6) were pregnant, nursing, planning for pregnancy, or unable to use effective contraceptive; 7) had medical conditions that were considered unsuitable for the trial by the investigators.

The screening and single-blind randomization were completed at the Department of Respiratory Medicine, Shanghai Pulmonary Hospital, Tongji University. The study has been approved by the Institutional Review Board of Shanghai Pulmonary Hospital (Approval No.: K14-156). The clinical trial has been registered at http://www.chictr. org.cn/enindex.aspx. (Trial registration No.: ChiCTROOC-15005818).

Patients' baseline data were collected and are presented in Table 1. Baseline data included gender, age, BMI, disease duration, SGRQ score, FVC, FEV1, DLCO, 6MWD, and lung volume calculated based on chest $\mathrm{X}$-ray results.

\subsection{Study Design and Randomization}

This was a single center, single blind randomized control trial. The random numbers were generated in SAS by the biostatisticians from Tongji University. The randomized results were concealed in opaque sealed envelopes prepared and shuffled before the start of the study by an independent person unrelated to the study protocol. The study schedule is displayed in Figure S3. Patients were screened, enrolled, and randomized. During the trial, patients were scheduled to have clinic visits at the $6^{\text {th }}$ and / or $12^{\text {th }}$ month. If patients developed IPF exacerbation during the trial, then the patients were withdrawn from the trial and treated immediately.

\subsection{Frequency and Management of the Breathing Exercise of LHP's RRPF}

Patients in the exercise group repeated the breathing exercise 3 times daily (4 to 6 minutes each time) and rested for one minute after each time. Two weeks before the trial started, patients assigned to the exercise group underwent breathing exercise training twice per week (at outpatient clinic or in hospital). The training was provided by the study investigators. The study investigators made sure that patients fully understood and learned the breathing exercises. After the trial started, patients in the exercise group provided video recording of their exercise to the investigators once per month. The investigators re-trained the patients if they found the patients did not execute the movements correctly. In each clinic visit, the investigators examined patients' breathing exercise, corrected movements, or re-trained the patients to make sure that the patients performed the breathing exercise correctly. Patients in the control group did not perform the breathing exercise and only came to the two clinic visits. Every patient wrote a diary following the study protocol during the trial. Patients continued their existing therapies during the trial at least for one year. Clinic visits were scheduled at the $6^{\text {th }}$ month and $12^{\text {th }}$ month of the trials. Some patients did not come to the $6^{\text {th }}$ month clinic visit and only returned to the $12^{\text {th }}$ month clinic visit.

\section{Effectiveness and Safety Assessment}

\subsection{Primary Endpoints}

The study primary endpoints were changes in FVC and lung volume. Lung function was determined according to the 2005 ATS/ERS Guidelines [16]. Changes in FVC after the breathing exercises was used to estimate the effectiveness of LHP's RRPF. Chest X-ray was performed at the beginning and end of the trial. Lung volume was determined by the position of the left and right transverses relative to the position of the posterior rib on the X-ray image. Changes in lung volume after the breathing exercises was measured.

\subsection{Secondary Endpoints}

The study secondary endpoints included $6 \mathrm{MWD}$, quality of life score (St. George's Respiratory Questionnaire, SGRQ score), forced expiratory volume in one second (FEV1), and diffusing capacity of the lungs for carbon monoxide (DLCO). 6MWD was determined according to the ATS Guidelines [17] in the study site. On the flat ground, patient walked back and forth along a 40-meter straight line for 6 minutes, and the walking distance was measured. $6 \mathrm{MWD}$ represents patient heart and lung function and physical activity endurance. The standard SGRQ [18] was used to assess the impact of the breathing exercise on the quality of life (QOL) of patients. FEV1 was determined according 
to the 2005 ATS/ERS Guidelines [16]. FEV1 represents airway ventilation function. DLCO represents oxygen exchange capacity and was used to estimate the effectiveness of LHP's RRPF.

\subsection{Safety Measurement}

Electrocardiogram (EKG) was performed to assess the effect of the breathing exercise on cardiac function. Patients underwent EKG at the beginning of the trial and the $6^{\text {th }}$ and $12^{\text {th }}$ month clinic visits.

\section{Statistical Analyses}

Paired t-test was used to compare the heart rate and blood oxygen saturation of healthy volunteers before the breathing exercise, right after the exercise, and one minute after the end of the exercise. Paired t-test was also used to compare the lung volume of healthy volunteers when doing the exercise versus when breathing calmly at the rest state (mean QLD\%).

Independent sample t-test was used to analyze the baseline data of enrolled patients, including age, BMI, gender, disease duration, SGRQ score, 6MWD, FVC, FEV1,
DLCO, and lung volume (left and right).

FVC, SGRQ, 6MWT, FEV1, and DLCO were measured at the beginning of the trial and the $6^{\text {th }}$ and $12^{\text {th }}$ month clinic visits. Of the 82 enrolled patients, 12 only had baseline data; 20 did not have the $6^{\text {th }}$ month clinic visit data; 11 did not have the $12^{\text {th }}$ month clinic visit data; 39 had complete data. The data value differences between the $6^{\text {th }}$ month clinic visit and the baseline and between the $12^{\text {th }}$ month clinic visit and the baseline were considered as effectiveness variables. The effectiveness variables were analyzed using linear mixed effect model. In this model, missing data were allowed; random data loss was assumed; the missing data were not imputed. Unstructured covariance matrix was used in the linear mixed effect model (likelihood-ratio is the minimal), $\mathrm{P}<0.05$ was considered significantly different. The statistical analysis software IBMSPSS24 was used.

A diary book was handed out to every study participant. All the study participants recorded the frequency, onset time, severity, and description of adverse events during the trial. Safety analysis was descriptive. 

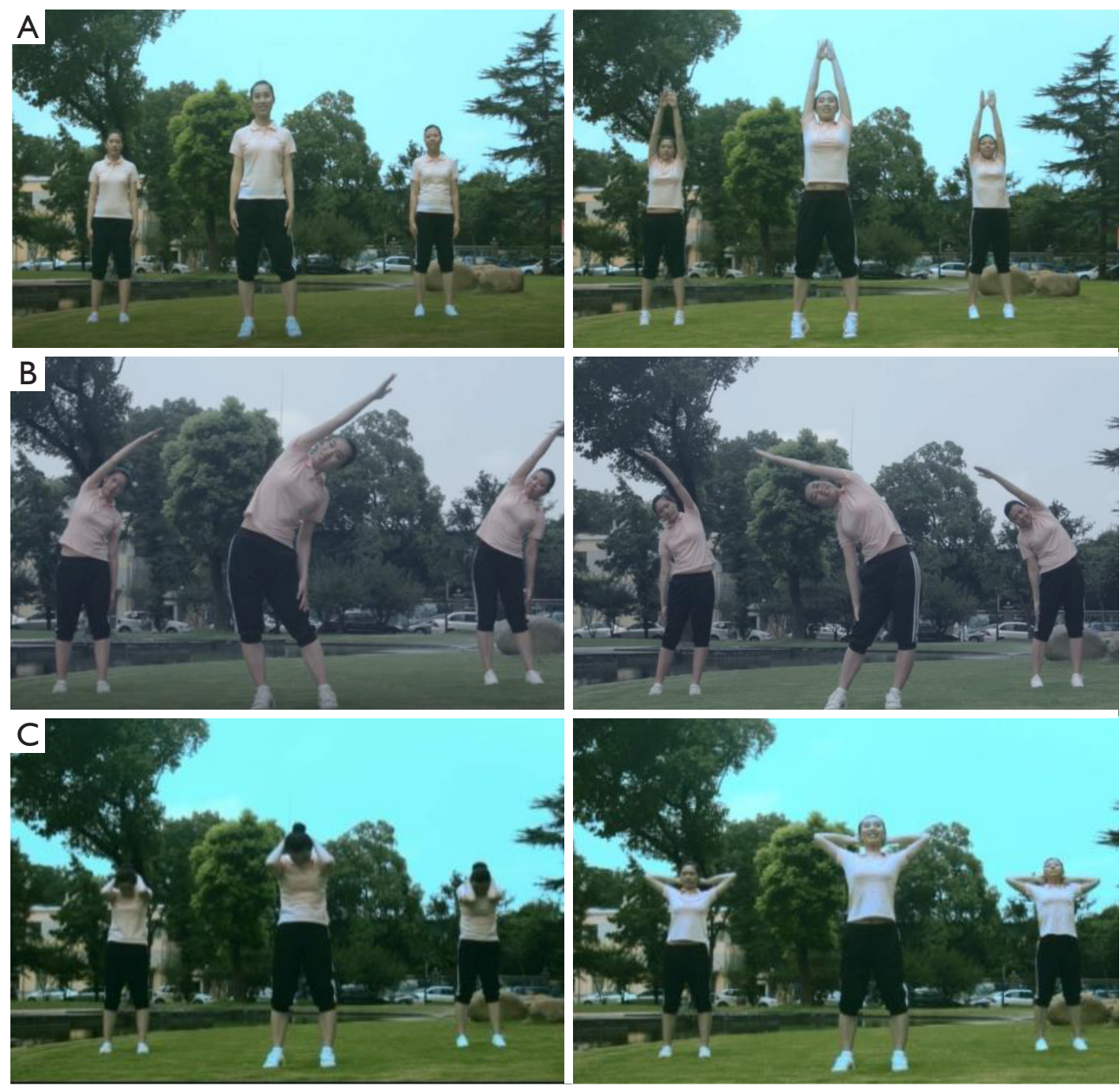

Figure S1 Illustration of breathing exercise of LHP's RRPF. (A) Deep breath of the whole lung. Patients raised both arms outward slowly and inhaled deeply till both hands closed over the top of the head. Subsequently, patients lowered both arms slowly and exhaled deeply till both arms returned to their original position. (B) Deep breath of unilateral lower lung. Patients raised one arm outward slowly, bended the torso toward the opposite direction to the arm to approximately $30-60^{\circ}$ angle, and inhaled deeply. Subsequently, patients exhaled deeply and lowered the arm to its original position. (C) Deep breath of upper lung. Patients crossed the two hands at the back of the neck, bended the head and neck forward, and exhaled deeply. Subsequently, patients kept the two hands crossed at the back of the neck, forced both arms backward, raised the head and neck slowly, and inhaled deeply. 

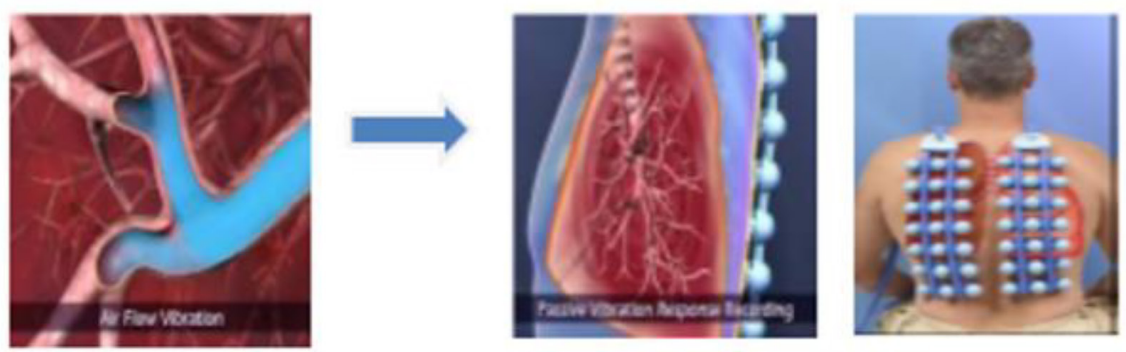

analog signal to digital signal
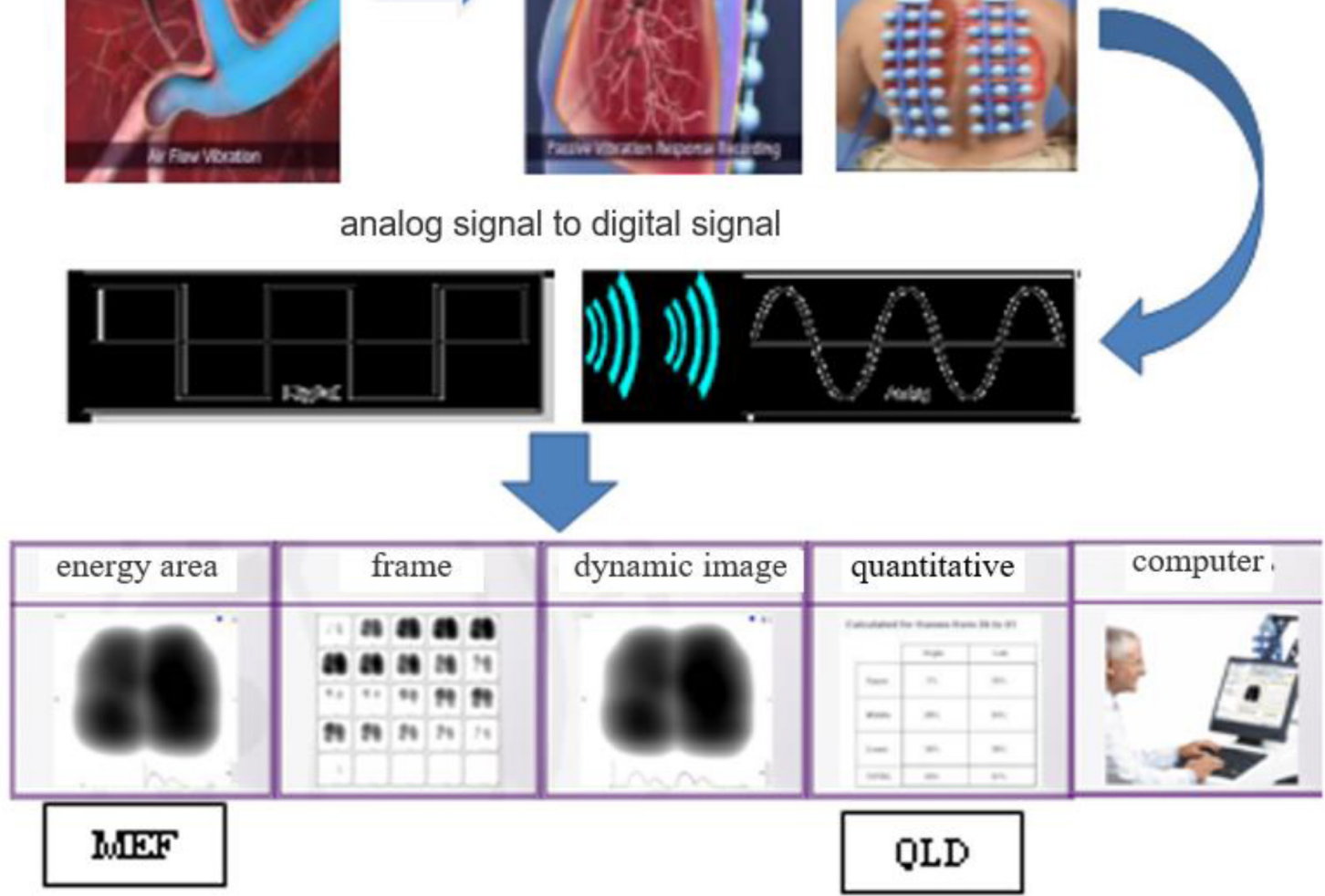

Figure S2 The principle of operation of vibration response imaging (VRI). The airflow distributed along the bronchial tree generates vibrations, which propagate through the soft tissue of the lungs and chest wall to the surface of the chest. The vibrational energy is captured by multiple acoustic sensors-microphones, and the captured energy is recorded as an analog signal. Through a specific algorithm-filtering, sampling, time division, and interpolation, data were used to create a real-time energy distribution plot and digital signals during breathing. MEF, maximum energy frame; QLD, quantitative lung data. 


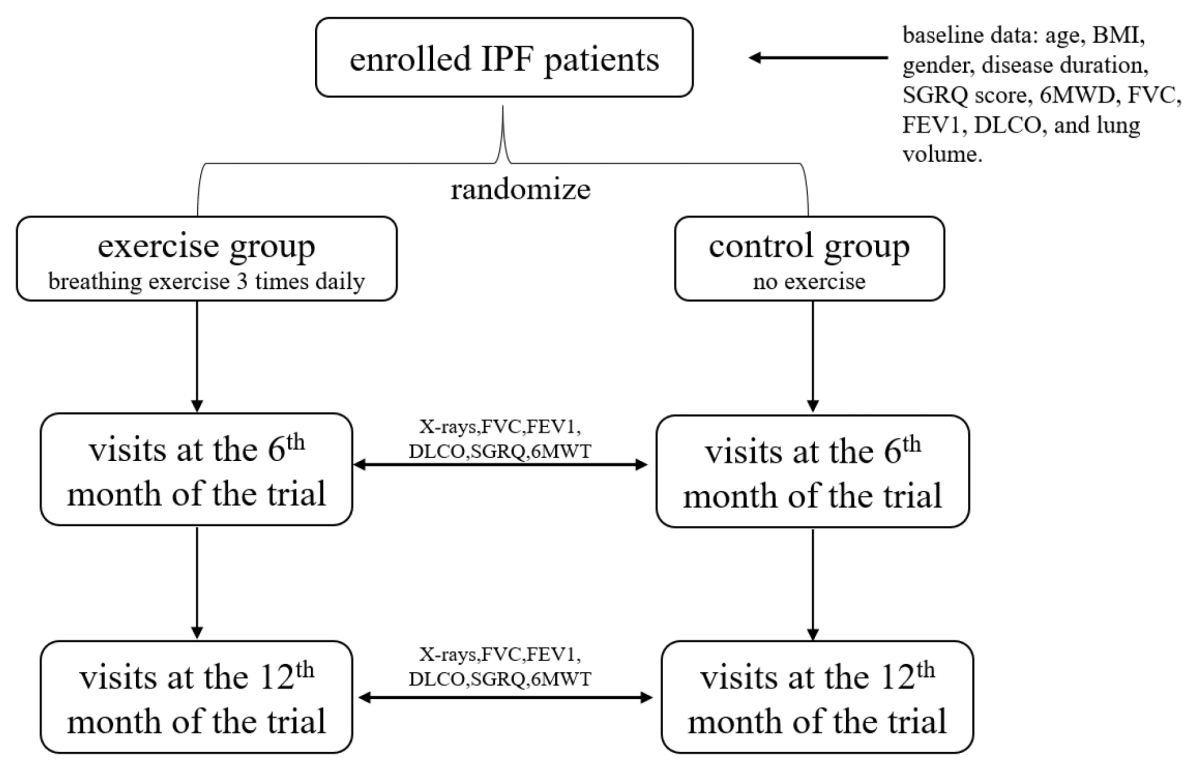

Figure S3 Study design and procedure. Enrolled patients with IPF were randomized to the exercise group and control group. Patients in both groups returned to clinic visits at the $6^{\text {th }}$ and $12^{\text {th }}$ month of the trial. Clinical data were collected during the clinic visits, and the data were compared with the baseline data. 


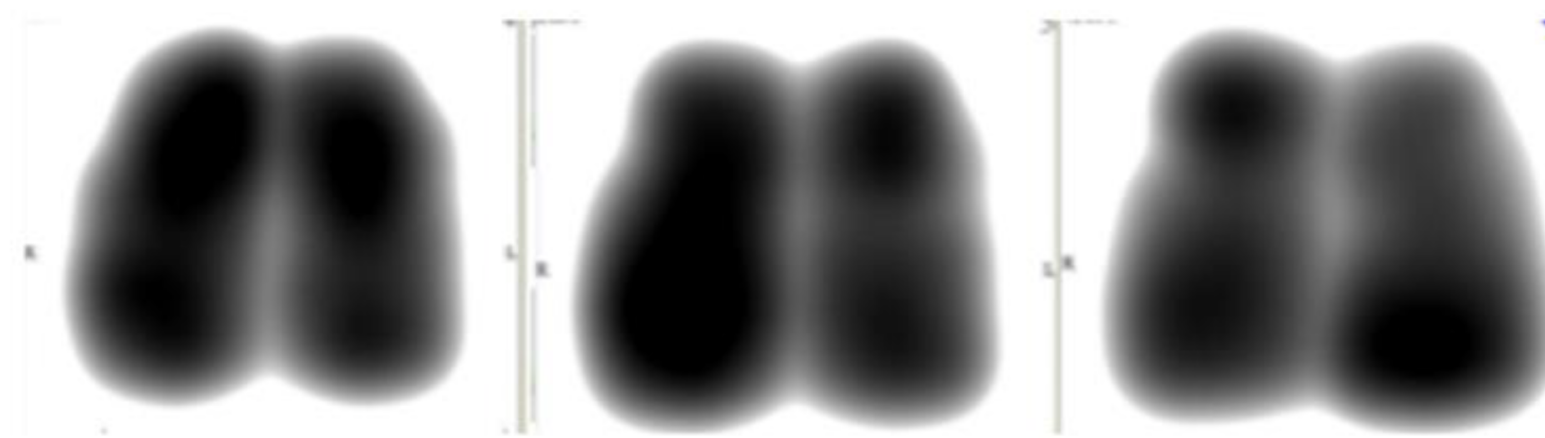

calm breathing both arms flatting both arms raising

\begin{tabular}{|c|c|c|c|c|c|c|c|c|}
\hline Comparison & $\begin{array}{l}\text { The left } \\
\text { lung }\end{array}$ & $\begin{array}{l}\text { Mean\% } \\
\text { During } \\
\text { exercise }\end{array}$ & $\begin{array}{l}\text { Mean\% at } \\
\text { rest }\end{array}$ & $P$ & $\begin{array}{l}\text { The righ } \\
\text { lung }\end{array}$ & $\begin{array}{l}\text { Mean\% } \\
\text { During } \\
\text { exercise }\end{array}$ & $\begin{array}{l}\text { Mean\% } \\
\text { rest }\end{array}$ & \\
\hline \multirow{3}{*}{$\begin{array}{l}\text { Both arms } \\
\text { parallel to } \\
\text { the ground }\end{array}$} & Upper & $9.25 \pm 3.3$ & $11.5 \pm 2.9$ & 0.032 & Upper & $8.2 \pm 4.4$ & $9.2 \pm 4.4$ & 0.41 \\
\hline & Middle & $18.3 \pm 4.4$ & $19.0 \pm 4.7$ & 0.332 & Middle & $18.8 \pm 5.1$ & $17.8 \pm 4.6$ & 0.271 \\
\hline & Lower & $22.5 \pm 4.2$ & $21.6 \pm 5.3$ & 0.553 & Lower & $23.0 \pm 6.3$ & $20.9 \pm 6.3$ & 0.103 \\
\hline \multirow{3}{*}{$\begin{array}{l}\text { Both arms } \\
\text { upward }\end{array}$} & Upper & $8.4 \pm 3.3$ & $11.5 \pm 2.9$ & 0.001 & Upper & $6.6 \pm 2.5$ & $9.2 \pm 4.4$ & 0.019 \\
\hline & Middle & $19.5 \pm 4.8$ & $19.0 \pm 4.7$ & 0.544 & Middle & $18 \pm 4.2$ & $17.8 \pm 4.6$ & 0.796 \\
\hline & Lower & $23.9 \pm 5.6$ & $21.6 \pm 5.3$ & 0.083 & Lower & $23.7 \pm 7.4$ & $20.9 \pm 6.3$ & 0.133 \\
\hline
\end{tabular}

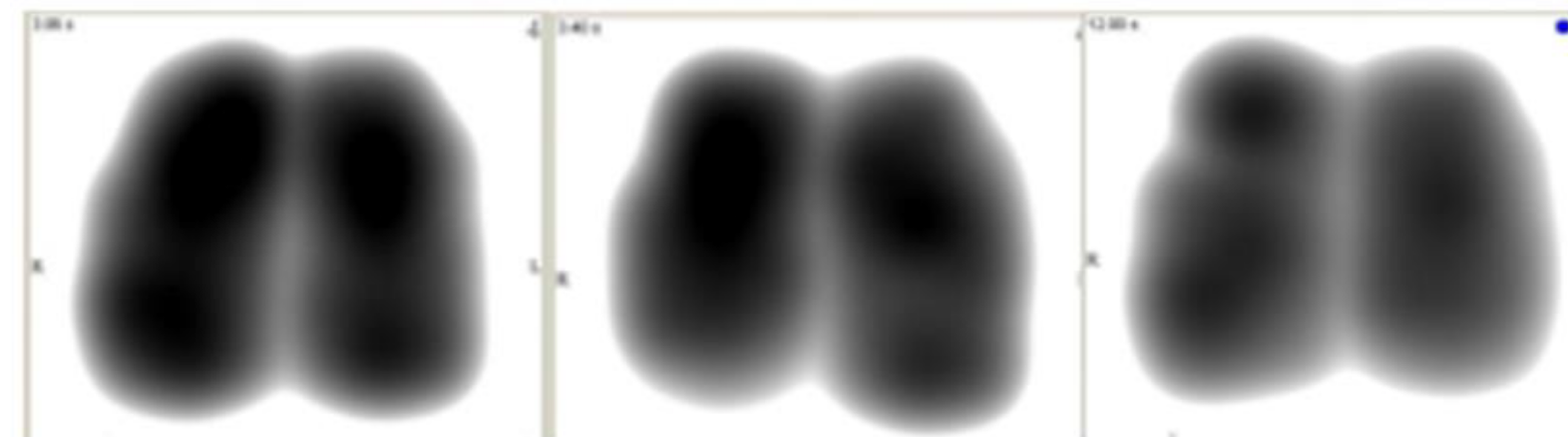

calm breathing

left arm raising

right arm raising

\begin{tabular}{|c|c|c|c|c|c|c|c|c|}
\hline Comparison & $\begin{array}{l}\text { The left } \\
\text { lung }\end{array}$ & $\begin{array}{l}\text { Mean\% } \\
\text { During } \\
\text { exercise }\end{array}$ & $\begin{array}{l}\text { Mean } \\
\% \quad \text { at } \\
\text { rest }\end{array}$ & $P$ & $\begin{array}{l}\text { The ri } \\
\text { lung }\end{array}$ & $\begin{array}{l}\text { Mean\% } \\
\text { During } \\
\text { exercise }\end{array}$ & $\begin{array}{l}\text { Mean\% } \\
\text { at rest }\end{array}$ & $p$ \\
\hline \multirow{3}{*}{$\begin{array}{l}\text { The left arm } \\
\text { was raised. }\end{array}$} & Upper & $8.7 \pm 3.3$ & $\begin{array}{l}11.5 \\
\pm 2.9\end{array}$ & 0.004 & Upper & $9.1 \pm 4.0$ & $9.2 \pm 4.4$ & 0.934 \\
\hline & Middle & $19.5 \pm 4.3$ & $\begin{array}{l}19.0 \\
\pm 4.7\end{array}$ & 0.527 & Middle & $17.1 \pm 3.6$ & $17.8 \pm 4.6$ & 50.588 \\
\hline & Lower & $23.6 \pm 6.6$ & $\begin{array}{l}21.6 \\
+5.3\end{array}$ & 0.309 & Lower & $21.6 \pm 5.8$ & $20.9 \pm 0.3$ & 0.594 \\
\hline \multirow{3}{*}{$\begin{array}{l}\text { The right } \\
\text { arm was } \\
\text { raised. }\end{array}$} & Upper & $11.7 \pm 3.7$ & $\begin{array}{l}11.5 \\
\pm 2.9\end{array}$ & 1.000 & Upper & $7.7 \pm 3.5$ & $9.2 \pm 4.4$ & 0.055 \\
\hline & Middle & $20.2 \pm 5.3$ & $\begin{array}{l}19.0 \\
4.7\end{array}$ & 0.259 & Middle & $15.5 \pm 3.6$ & $17.8 \pm 4.6$ & 50.071 \\
\hline & Lower & $22.0 \pm 6.0$ & $\begin{array}{l}21.6 \\
+5.3\end{array}$ & 0.800 & Lower & $23.0 \pm 6.3$ & $20.9 \pm 6.3$ & 0.176 \\
\hline
\end{tabular}

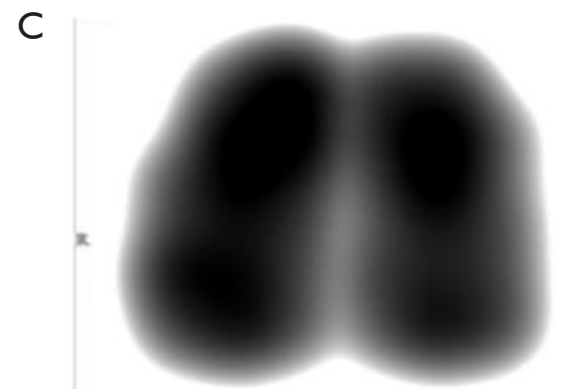

calm breathing

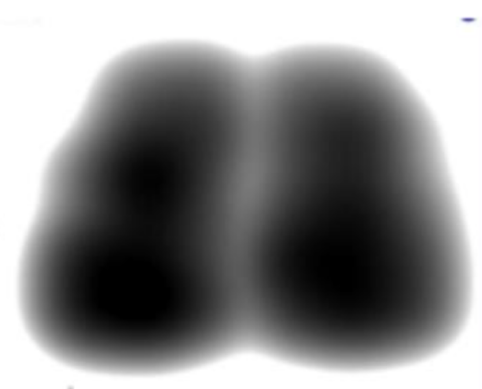

bended the head and neck forward

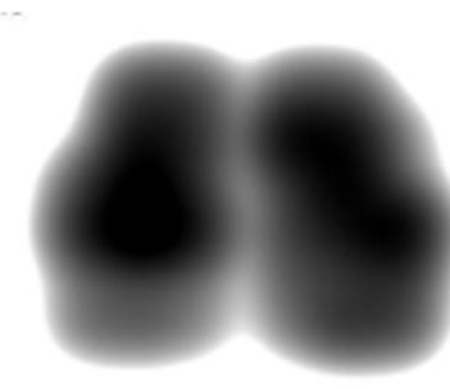

bended the head and neck backward

\begin{tabular}{|l|l|l|l|l|l|l|l|l|}
\hline \multirow{2}{*}{ Comparison } & $\begin{array}{l}\text { The } \\
\text { left } \\
\text { lung }\end{array}$ & $\begin{array}{l}\text { Mean\% } \\
\text { During } \\
\text { exercise }\end{array}$ & $\begin{array}{l}\text { Mean\% } \\
\text { at rest }\end{array}$ & $P$ & $\begin{array}{l}\text { The } \\
\text { lung }\end{array}$ & $\begin{array}{l}\text { Mean } \\
\text { During } \\
\text { exercise }\end{array}$ & $\begin{array}{l}\text { Mean\% } \\
\text { at rest }\end{array}$ & $P$ \\
\hline \multirow{2}{*}{$\begin{array}{l}\text { The head and neck } \\
\text { were bended forward }\end{array}$} & Upper & $12.9 \pm 3.2$ & $11.5 \pm 2.9$ & 0.458 & Upper & $11.4 \pm 4.8$ & $9.2 \pm 4.4$ & 0.168 \\
\cline { 2 - 9 } & Middle & $18.9 \pm 5.0$ & $19.0 \pm 4.7$ & 0.684 & Middle & $15.7 \pm 5.2$ & $17.8 \pm 4.60 .248$ \\
\cline { 2 - 9 } & Lower & $21.3 \pm 7.4$ & $21.6 \pm 5.3$ & 0.397 & Lower & $20.3 \pm 7.1$ & $20.9 \pm 6.3$ & 0.846 \\
\hline \multirow{2}{*}{$\begin{array}{l}\text { The head and neck } \\
\text { were } \\
\text { backward. }\end{array}$} & Upper & $13.7 \pm 3.4$ & $11.5 \pm 2.9$ & 0.122 & Upper & $11.3 \pm 1.2$ & $9.2 \pm 4.4$ & 0.116 \\
\cline { 2 - 9 } & Middle & $19.9 \pm 5.3$ & $19.0 \pm 4.7$ & 0.383 & Middle & $18.3 \pm 3.1$ & $17.8 \pm 4.60 .581$ \\
\cline { 2 - 9 } & Lower & $20.5 \pm 6.1$ & $21.6 \pm 5.3$ & 0.107 & Lower & $16.5 \pm 7.0$ & $20.9 \pm 6.3$ & 1.000 \\
\hline
\end{tabular}

Figure S4 Healthy volunteers' QLD, MEF, and EVP. (A) VRI-MEF during deep breath of the whole lung. The 3 photos are maximum energy frames (MEF) during deep breathing using the whole lung when the Subject was at rest state, kept both arms parallel to the ground, and raised both arms upward, respectively. The table displays the mean quantitative lung data (QLD)\% of bilateral lung volume when both arms were kept parallel to the ground and when both arms were raised upward. P values were calculated from statistical analyses. (The whole lung QLD is 100\%, which is the total sum of the left upper, middle, and lower lung and the right upper, middle, and lower lung.). (B) VRIMEF during deep breath of unilateral lower lung. The 3 photos are maximum energy frames (MEF) during deep breathing using unilateral lower lung when the subject was at rest state, raised the left arm, and raised the right arm, respectively. The table displays the mean quantitative lung data (QLD)\% of bilateral lung volume when the subjects raised the left arm and when the subjects raised the right arm. P values were calculated from statistical analyses. (The whole lung QLD is $100 \%$, which is the total sum of the left upper, middle, and lower lung and the right upper, middle, and lower lung.). (C) VRI-MEF during deep breath of upper lower lung. The 3 photos are maximum energy frames (MEF) during deep breathing using the upper lung when the subject was at rest state, bended the head and neck forward, and stretched the head and neck backward, respectively. The table displays the mean quantitative lung data (QLD)\% of bilateral lung volume when the subjects bended the head and neck forward and stretched the head and neck backward. P values were calculated from statistical analyses. (The whole lung QLD is 100\%, which is the total sum of the left upper, middle, and lower lung and the right upper, middle, and lower lung. 
Table S1 Safety of LHP's RRPF in healthy volunteers

\begin{tabular}{llll}
\hline Parameters & Time of the measurement & Hear rate (mean \pm standard deviation) & $P$ \\
\hline Heart rate & Right after the exercise/rest state & $90.95 \pm 11.26 / 78.45 \pm 11.52$ & $<0.001$ \\
& One minute after the exercise/rest state & $79.05 \pm 11.21 / 78.45 \pm 11.52$ & 0.447 \\
Blood oxygen & Right after the exercise/rest state & $98.10 \pm 1.71 / 98.45 \pm 0.95$ & 0.420 \\
saturation & One minute after the exercise/rest state & $98.70 \pm 0.57 / 98.45 \pm 0.95$ & 0.204 \\
\hline
\end{tabular}

LHP's RRPF, LHP's respiratory rehabilitation for pulmonary fibrosis.
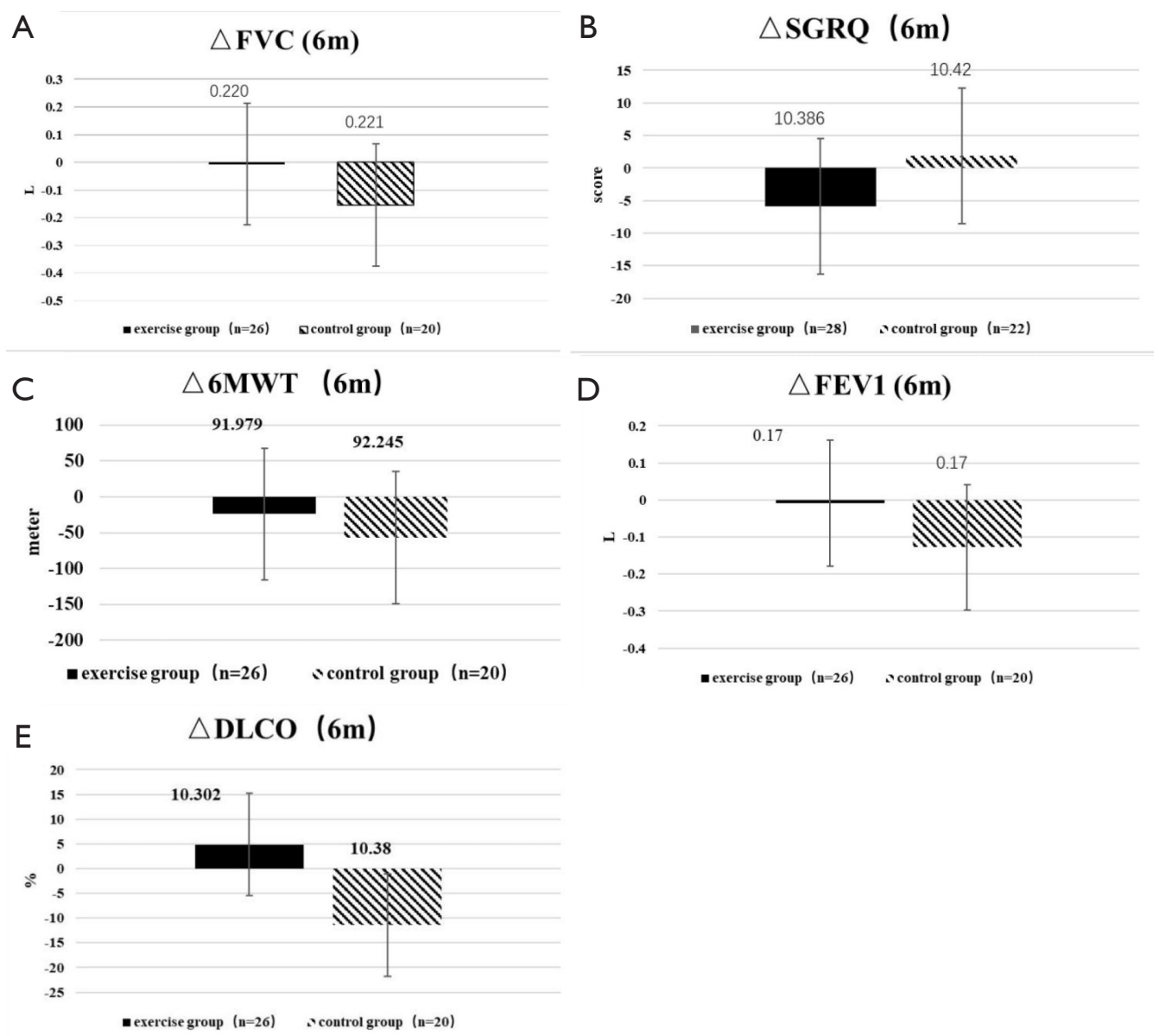

Figure S5 Comparison of $\triangle \mathrm{FVC}, \triangle \mathrm{SGRQ}, \triangle 6 \mathrm{MWD}, \triangle \mathrm{FEV} 1$, and $\triangle \mathrm{DLCO}$ at the $6^{\text {th }}$ month $(6 \mathrm{~m})$ Clinic Visit of the Exercise Group Versus the Control Group. (A) Comparison of $\triangle \mathrm{FVC}$ at the $6^{\text {th }}$ month $(6 \mathrm{~m})$ Clinic Visit of the Exercise Group (n=26) Versus the Control Group $(\mathrm{n}=20)(\mathrm{P}=0.023)$. The Y-axis represents changes in FVC $(\Delta \mathrm{FVC}) . \Delta \mathrm{FVC}=$ the $\mathrm{FVC}$ values at the $6^{\text {th }}$ month clinic visit $-\mathrm{FVC}$ values at the baseline. The data are presented as mean $\triangle \mathrm{FVC} \pm$ standard deviation. (B) Comparison of $\Delta \mathrm{SGRQ}$ at the $6^{\text {th }}$ Month Clinic Visit of the Exercise Group ( $\mathrm{n}=28)$ Versus the Control Group $(\mathrm{n}=22)(\mathrm{P}=0.016)$. The Y-axis represents changes in SGRQ $(\Delta \mathrm{SGRQ}) . \Delta \mathrm{SGRQ}=$ the SGRQ values at the $6^{\text {th }}$ month clinic visit - SGRQ values at the baseline. The data are presented as mean $\triangle \mathrm{SGRQ} \pm$ standard deviation. (C) Comparison of $\triangle 6 M W D$ at the $6^{\text {th }}$ Month $(6 \mathrm{~m})$ Clinic Visit of the Exercise Group ( $\left.\mathrm{n}=28\right)$ Versus the Control Group ( $\left.\mathrm{n}=22\right)(\mathrm{P}=0.266)$. The Y-axis represents changes in $6 \mathrm{MWD}(\Delta 6 \mathrm{MWD}) . \Delta 6 \mathrm{MWD}=$ the $6 \mathrm{MWD}$ values at the $6^{\text {th }}$ month clinic visit $-6 \mathrm{MWD}$ values at the baseline. The data are presented as mean $\triangle 6 \mathrm{MWD} \pm$ standard deviation. (D) Comparison of $\Delta \mathrm{FEV} 1$ at the $6^{\text {th }}$ Month $(6 \mathrm{~m})$ Clinic Visit of the Exercise Group ( $\mathrm{n}=26)$ Versus the Control Group $(\mathrm{n}=20)(\mathrm{P}=0.017)$. The Y-axis represents changes in FEV1 $(\Delta \mathrm{FEV} 1) . \Delta \mathrm{FEV} 1=$ the FEV1 values at the $6^{\text {th }}$ month clinic visit $-\mathrm{FEV} 1$ values at the baseline. The data are presented as mean $\triangle \mathrm{FEV} 1 \pm$ standard deviation. (E) Comparison of $\triangle \mathrm{DLCO}$ at the $6^{\text {th }}$ Month (6m) Clinic Visit of the Exercise Group ( $\left.\mathrm{n}=26\right)$ Versus the Control Group $(\mathrm{n}=20)(\mathrm{P}<0.001)$. The $\mathrm{Y}$-axis represents changes in DLCO $(\triangle \mathrm{DLCO}) . \triangle \mathrm{DLCO}=$ the DLCO values at the $6^{\text {th }}$ month clinic visit $-\mathrm{DLCO}$ values at the baseline. The data are presented as mean $\triangle \mathrm{DLCO} \pm$ standard deviation. SGRQ, St. George's Respiratory Questionnaire; 6MWD, six-minute walk distance; FVC, forced vital capacity; FEV1, forced expiratory volume in one second; DLCO, diffusing capacity of the lungs for carbon monoxide. 


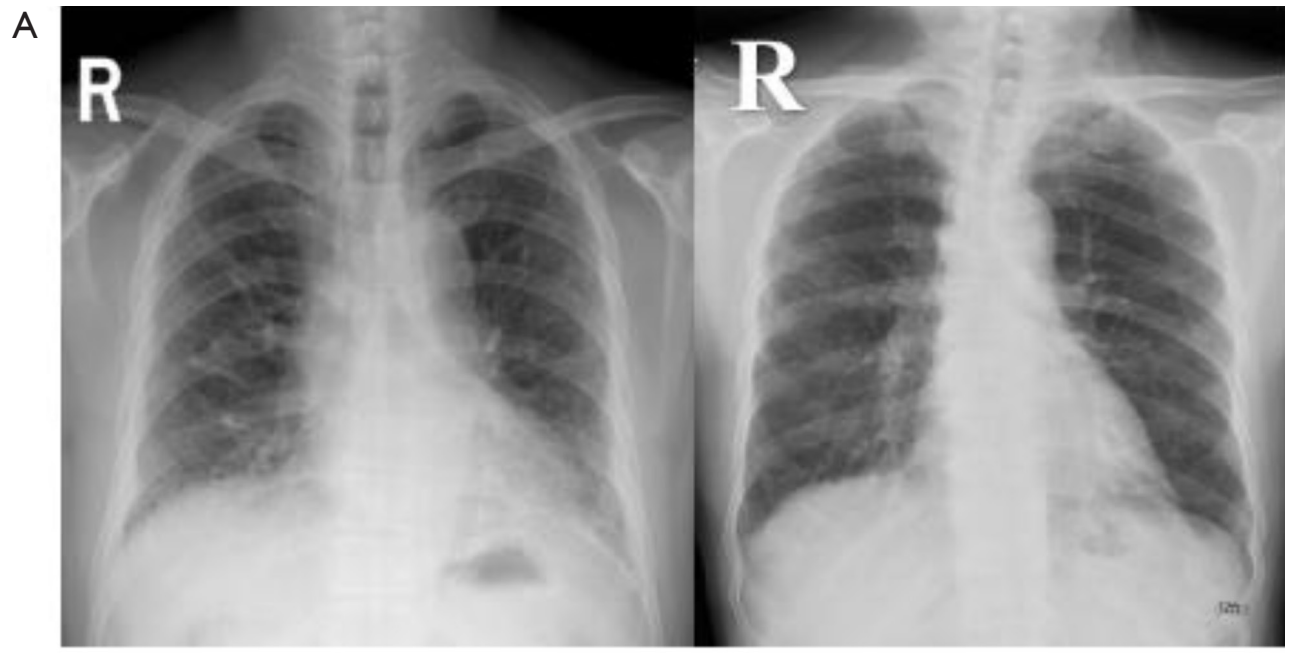

Left panel: Chest $X$-ray at the beginning of the trial

Right panel: Chest X-ra at the $12^{\text {th }}$ month of the trial

The $\mathrm{R}$ on the figure means right side of the chest.

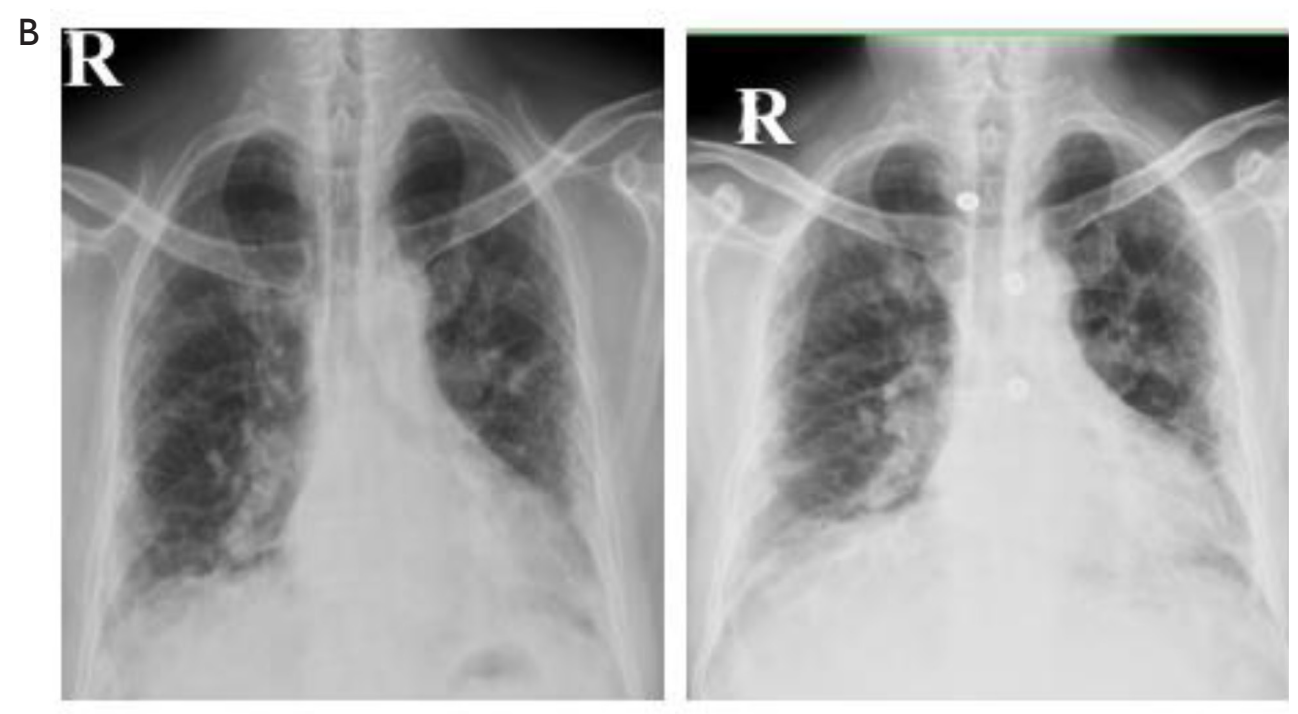

Left panel: Chest $\mathrm{X}$-ray at the beginning of the trial

Right panel: Chest $\mathrm{X}$-ra at the $12^{\text {th }}$ month of the trial

The $\mathrm{R}$ on the figure means right side of the chest.

Figure S6 Chest X-ray images at the $12^{\text {th }}$ month $(12 \mathrm{~m}$ ) visit. (A) Increased lung volume of a patient from the exercise Group. (B) Reduced lung volume of a patient from the control group. 


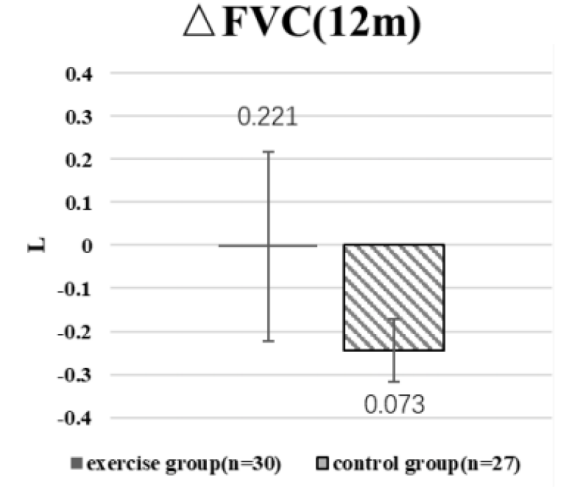

C $\triangle$ SGRQ (12m)

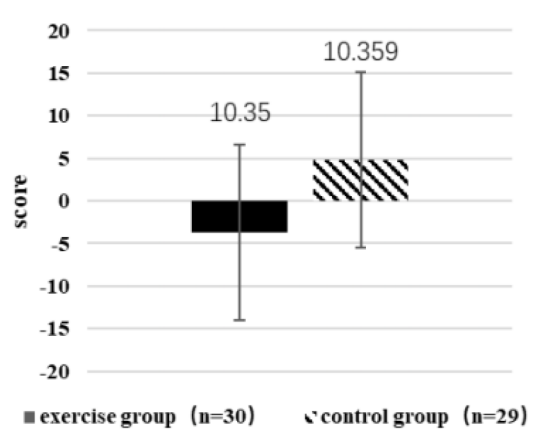

- exercise group $(\mathrm{n}=30) \quad$ scontrol group $(\mathrm{n}=29)$
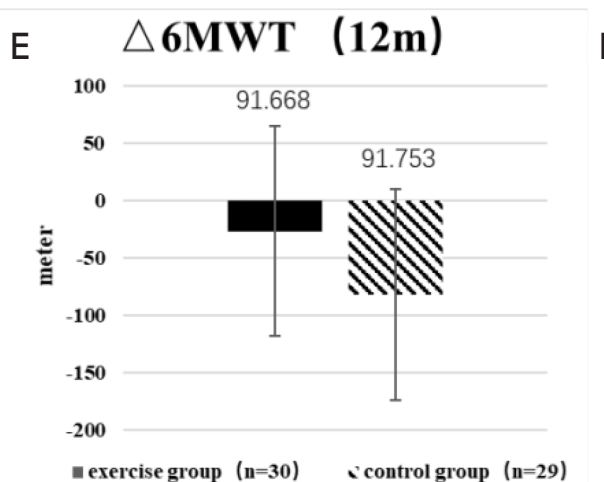

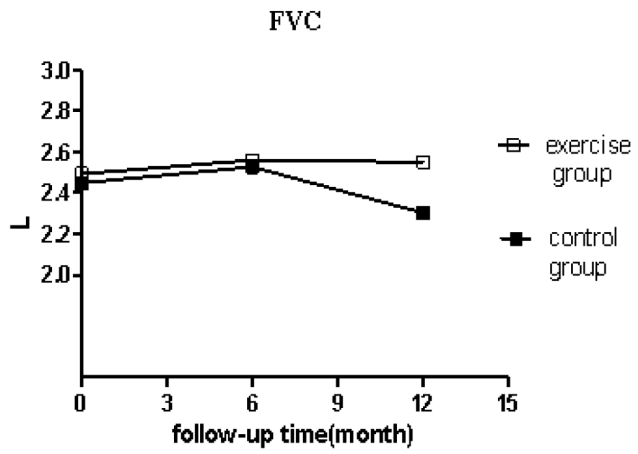

D

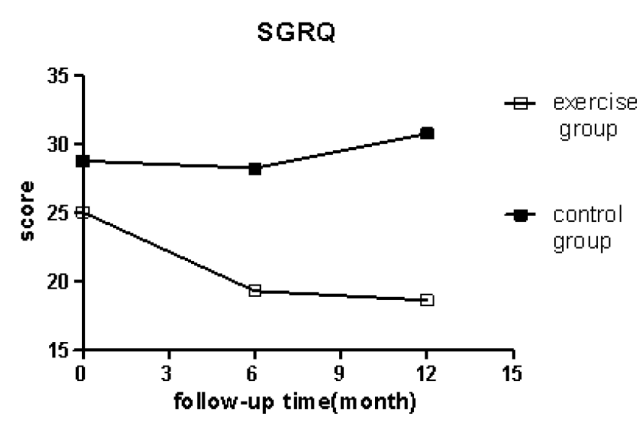

$\mathrm{F}$

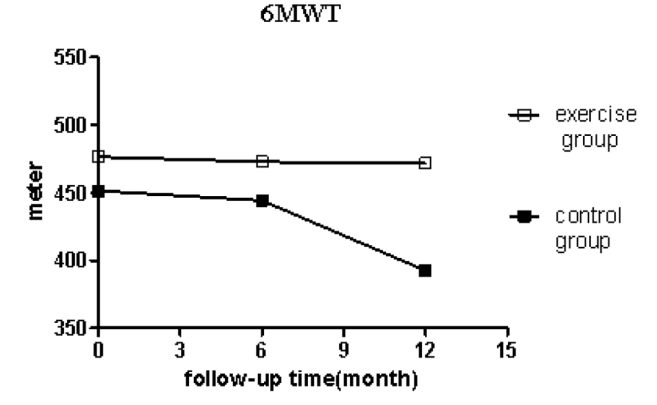

$\mathrm{H}$

G
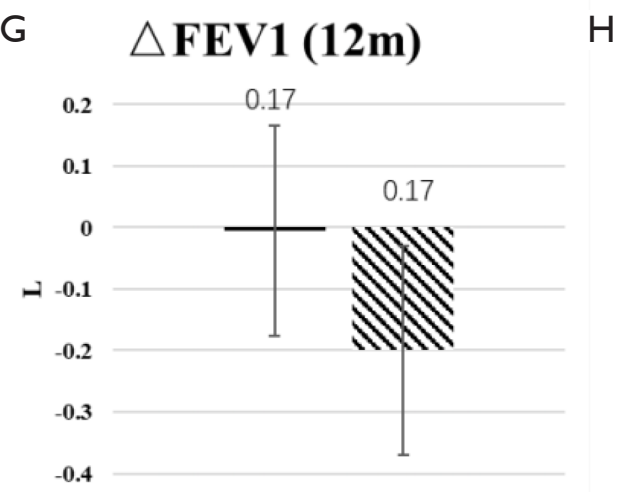

- exercise group $(\mathrm{n}=\mathbf{3 0}) \quad$ =control group $(\mathrm{n}=\mathbf{2 7})$

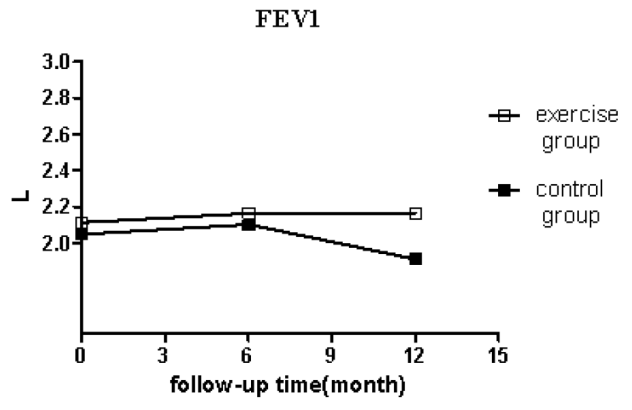

I $\triangle$ DLCO $(12 \mathrm{~m})$
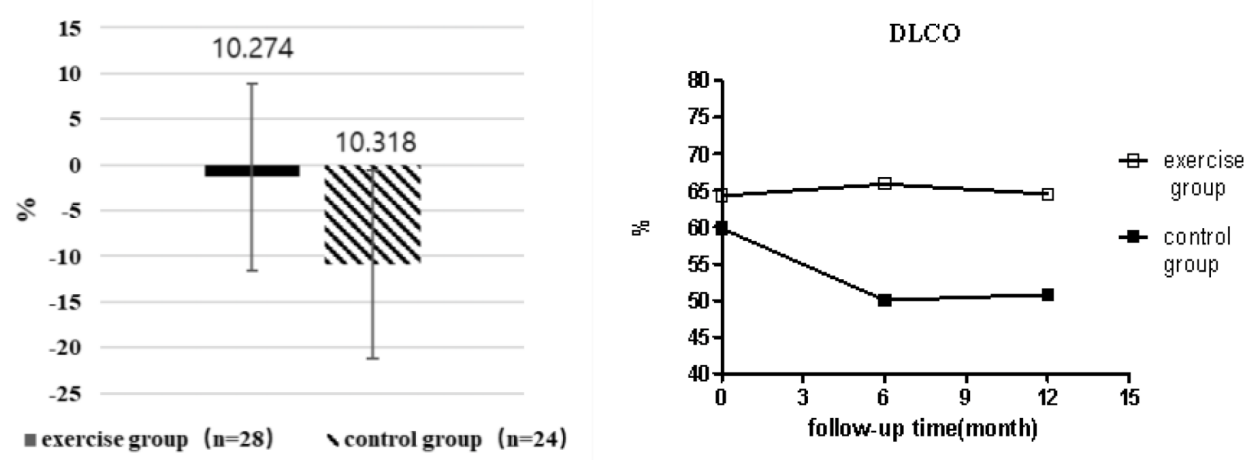

Figure S7 Comparison of $\triangle \mathrm{FVC}, \triangle \mathrm{SGRQ}, \triangle 6 \mathrm{MWD}, \triangle \mathrm{FEV} 1$, and $\triangle \mathrm{DLCO}$ at the $12^{\text {th }}$ month $(12 \mathrm{~m})$ Clinic Visit of the Exercise Group Versus the Control Group. (A,B). Comparison of $\triangle \mathrm{FVC}$ at the $12^{\text {th }}$ month $(12 \mathrm{~m})$ Clinic Visit of the Exercise Group (n=30) Versus the Control Group ( $\mathrm{n}=27)(\mathrm{P}=0.001)$. (A) The $\mathrm{Y}$-axis represents changes in $\mathrm{FVC}(\Delta \mathrm{FVC}) ; \Delta \mathrm{FVC}=$ the $\mathrm{FVC}$ values at the $12^{\text {th }}$ month clinic visit - FVC values at the baseline; the data are presented as mean $\triangle \mathrm{FVC} \pm$ standard deviation. (B) X-axis is the time of the trial; Y-axis is FVC; the data are presented as mean FVC. (C,D) Comparison of $\triangle \mathrm{SGRQ}$ at the $12^{\text {th }}$ Month Clinic Visit of the Exercise Group (n=30) Versus the Control Group $(\mathrm{n}=29)(\mathrm{P}=0.003)$. (C) The Y-axis represents changes in SGRQ $(\Delta \mathrm{SGRQ}) ; \Delta \mathrm{SGRQ}=$ the SGRQ values at the $12^{\text {th }}$ month clinic visit - SGRQ values at the baseline; the data are presented as mean $\triangle \mathrm{SGRQ}+$ standard deviation. (D) $\mathrm{X}$-axis is the time of the trial; Y-axis is SGRQ score; the data are presented as mean SGRQ score. (E,F) Comparison of $\triangle 6 M W D$ at the $12^{\text {th }}$ Month (12 m) Clinic Visit of the Exercise Group ( $\mathrm{n}=30)$ Versus the Control Group ( $\mathrm{n}=30)(\mathrm{P}=0.041)$. (E) The Y-axis represents changes in 6MWD ( $66 \mathrm{MWD}) ; \Delta 6 M W D$ $=$ the $6 \mathrm{MWD}$ values at the $12^{\text {th }}$ month clinic visit $-6 \mathrm{MWD}$ values at the baseline; the data are presented as mean $\triangle 6 \mathrm{MWD} \pm$ standard deviation. (F) X-axis is the time of the trial; $\mathrm{Y}$-axis is $6 \mathrm{MWD}$; the data are presented as mean $6 \mathrm{MWD}$. (G,H) Comparison of $\Delta \mathrm{FEV} 1$ at the $12^{\text {th }}$ Month (12m) Clinic Visit of the Exercise Group ( $\left.\mathrm{n}=30\right)$ Versus the Control Group ( $\left.\mathrm{n}=27\right)(\mathrm{P}=0.001)$. (G) The Y-axis represents changes in FEV1 $(\triangle \mathrm{FEV} 1) ; \triangle \mathrm{FEV} 1=$ the $\mathrm{FEV} 1$ values at the $12^{\text {th }}$ month clinic visit $-\mathrm{FEV} 1$ values at the baseline; the data are presented as mean $\triangle \mathrm{FEV} 1 \pm$ standard deviation. $(\mathrm{H}) \mathrm{X}$-axis is the time of the trial; $\mathrm{Y}$-axis is FEV1; the data are presented as mean FEV1. (I,J). Comparison of $\triangle \mathrm{DLCO}$ at the $12^{\text {th }}$ month (12m) Clinic Visit of the Exercise Group ( $\left.\mathrm{n}=28\right)$ Versus the Control Group $(\mathrm{n}=24)(\mathrm{P}=0.003)$. (I) The Y-axis represents changes in DLCO $(\triangle \mathrm{DLCO}) ; \triangle \mathrm{DLCO}=$ the DLCO values at the $12^{\text {th }}$ month clinic visit - DLCO values at the baseline; the data are presented as mean $\triangle \mathrm{DLCO} \pm$ standard deviation. (J) $\mathrm{X}$-axis is the time of the trial; Y-axis is DLCO; the data are presented as mean DLCO. Two patients from the exercise group and 5 from the control group did not have the $12^{\text {th }}$ month DLCO. SGRQ, St. George's Respiratory Questionnaire; 6MWD, six-minute walk distance; FVC, forced vital capacity; FEV1, forced expiratory volume in one second; DLCO, diffusing capacity of the lungs for carbon monoxide. 
Table S2 The number of patients developed acute exacerbation during the trial

\begin{tabular}{lccc}
\hline Group & With acute exacerbation & No acute exacerbation & Total \\
\hline Exercise & 3 & 36 & 39 \\
Control & 9 & 34 & 43 \\
Total & 12 & 70 & 82 \\
\hline
\end{tabular}

$\chi^{2}$ test $P=0.090$.

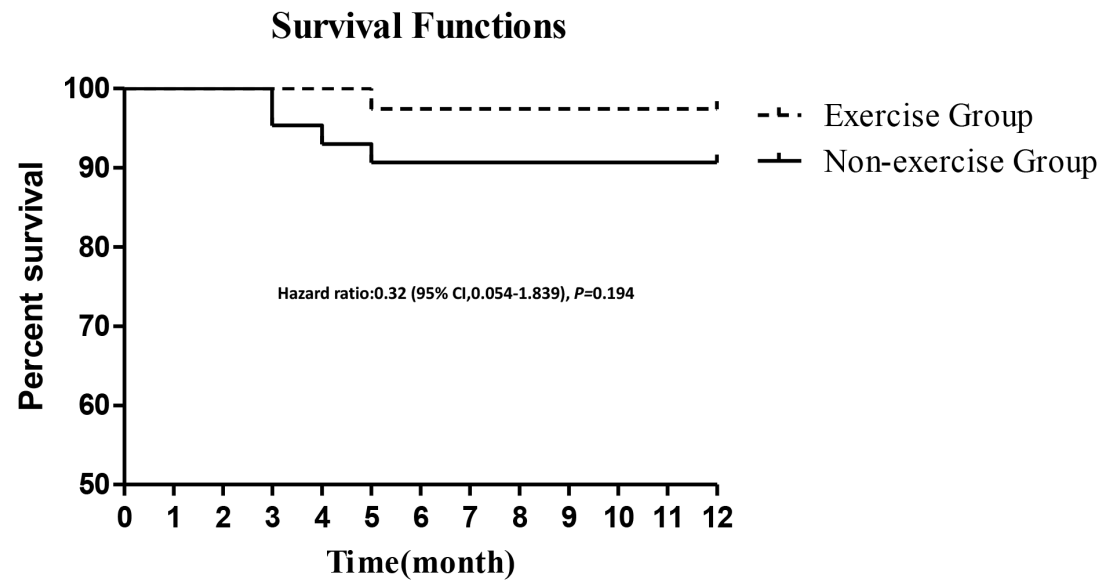

\begin{tabular}{llllllll}
\hline Month & 0 & 3 & 4 & 5 & 6 & 10 & 12 \\
\hline Exercise group & 39 & 39 & 39 & 38 & 38 & 38 & 38 \\
Control group & 43 & 41 & 40 & 39 & 39 & 39 & 39 \\
\hline
\end{tabular}

Figure S8 The 12-month $(12 \mathrm{~m})$ survival curve of patients from the exercise and control groups ( $\mathrm{n}=82)$. The $\mathrm{X}$-axis is month, and the $\mathrm{Y}$-axis is the percentage of survival. The table presents the number of the survived patients in each month.

Table S3 Mortality of the exercise and control groups

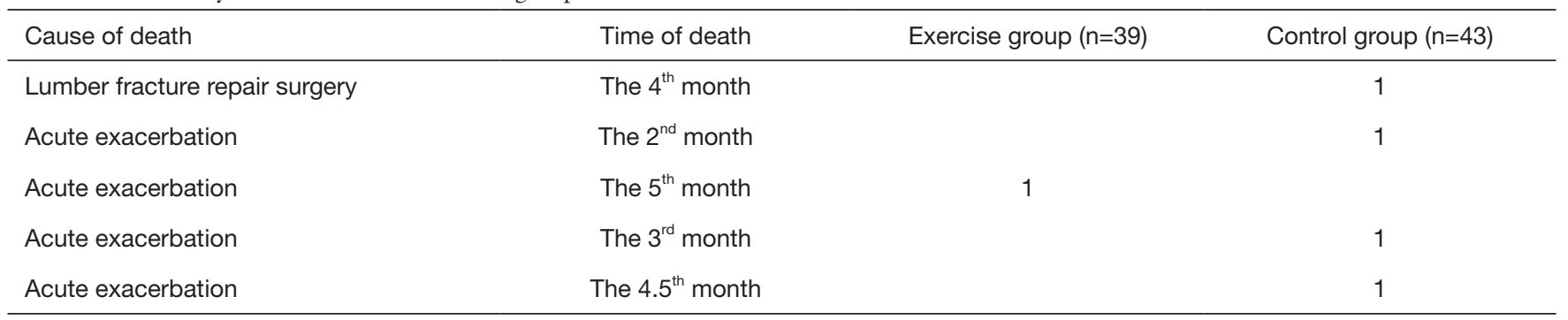

